\title{
Acidotolerant Bacteria and Fungi as a Sink of Methanol-Derived Carbon in a Deciduous Forest Soil
}

\author{
Mareen Morawe ${ }^{1 *}$, Henrike Hoeke ${ }^{2,3}$, Dirk K. Wissenbach ${ }^{4}$, Guillaume Lentendu ${ }^{5}$, \\ Tesfaye Wubet ${ }^{6}$, Eileen Kröber ${ }^{7}$ and Steffen Kolb ${ }^{1,7 *}$
}

' Department of Ecological Microbiology, University of Bayreuth, Bayreuth, Germany, ${ }^{2}$ Department of Molecular Systems Biology, Helmholtz Centre for Environmental Research, Leipzig, Germany, ${ }^{3}$ Department of Pharmaceutical and Medicinal Chemistry, Institute of Pharmacy, University of Leipzig, Leipzig, Germany, ${ }^{4}$ Institute of Forensic Medicine, University Hospital Jena, Jena, Germany, ${ }^{5}$ Department of Ecology, University of Kaiserslautern, Kaiserslautern, Germany, ${ }^{6}$ Department of Soil Ecology, Helmholtz Centre for Environmental Research, Leipzig, Germany, ${ }^{7}$ Institute of Landscape Biogeochemistry, Leibniz Centre for Landscape Research, Müncheberg, Germany

\section{OPEN ACCESS}

Edited by:

Svetlana N. Dedysh,

Winogradsky Institute of Microbiology (RAS), Russia

Reviewed by:

Marc Gregory Dumont,

University of Southampton,

United Kingdom

Marina G. Kalyuzhanaya

San Diego State University, United States

*Correspondence:

Mareen Morawe

mareen.morawe@uni-bayreuth.de Steffen Kolb kolb@zalf.de

Specialty section: This article was submitted to

Terrestrial Microbiology, a section of the journal

Frontiers in Microbiology

Received: 18 March 2017 Accepted: 05 July 2017

Published: 24 July 2017

Citation:

Morawe M, Hoeke $H$,

Wissenbach DK, Lentendu G, Wubet T, Kröber E and Kolb S (2017) Acidotolerant Bacteria and Fungi as a Sink of Methanol-Derived Carbon

in a Deciduous Forest Soil.

Front. Microbiol. 8:1361.

doi: 10.3389/fmicb.2017.01361
Methanol is an abundant atmospheric volatile organic compound that is released from both living and decaying plant material. In forest and other aerated soils, methanol can be consumed by methanol-utilizing microorganisms that constitute a known terrestrial sink. However, the environmental factors that drive the biodiversity of such methanol-utilizers have been hardly resolved. Soil-derived isolates of methanolutilizers can also often assimilate multicarbon compounds as alternative substrates. Here, we conducted a comparative DNA stable isotope probing experiment under methylotrophic (only $\left[{ }^{13} \mathrm{C}_{1}\right]$-methanol was supplemented) and combined substrate conditions $\left(\left[{ }^{12} \mathrm{C}_{1}\right]\right.$-methanol and alternative multi-carbon $\left[{ }^{13} \mathrm{C}_{\mathrm{u}}\right]$-substrates were simultaneously supplemented) to (i) identify methanol-utilizing microorganisms of a deciduous forest soil (European beech dominated temperate forest in Germany), (ii) assess their substrate range in the soil environment, and (iii) evaluate their trophic links to other soil microorganisms. The applied multi-carbon substrates represented typical intermediates of organic matter degradation, such as acetate, plant-derived sugars (xylose and glucose), and a lignin-derived aromatic compound (vanillic acid). An experimentally induced $\mathrm{pH}$ shift was associated with substantial changes of the diversity of active methanol-utilizers suggesting that soil $\mathrm{pH}$ was a niche-defining factor of these microorganisms. The main bacterial methanol-utilizers were members of the Beijerinckiaceae (Bacteria) that played a central role in a detected methanol-based food web. A clear preference for methanol or multi-carbon substrates as carbon source of different Beijerinckiaceae-affiliated phylotypes was observed suggesting a restricted substrate range of the methylotrophic representatives. Apart from Bacteria, we also identified the yeasts Cryptococcus and Trichosporon as methanol-derived carbon-utilizing fungi suggesting that further research is needed to exclude or prove methylotrophy of these fungi.

Keywords: DNA stable isotope probing, mxaF, bacterial 16S rRNA gene, fungal ITS, pH, high-throughput sequencing 


\section{INTRODUCTION}

Methanol is an abundant volatile organic compound (VOC) in the troposphere, i.e., reaches mixing ratios of up to $10 \mathrm{ppb}$. Due to its high reactivity, methanol impacts on the oxidative capacity, the formation of ozone, and pools of important organic reactants in the atmosphere (Galbally and Kirstine, 2002; Wohlfahrt et al., 2015). Atmospheric methanol mainly originates from growing plants and decaying plant material but originates to a smaller extent from reactions of methyl peroxy radicals in the troposphere (Fall and Benson, 1996; Warneke et al., 1999; Galbally and Kirstine, 2002; Millet et al., 2008; Wohlfahrt et al., 2015). Large sinks for atmospheric methanol are reactions with hydroxyl radicals and oceanic uptake, including contributions of microorganisms (Millet et al., 2008). The role of methylotrophic microorganisms in terrestrial ecosystems as global sinks of methanol is nonetheless undisputed (Kolb, 2009; Stacheter et al., 2013; Wohlfahrt et al., 2015). However, their environmental controls, their distribution in the phyllo- and rhizosphere, and their diversity in different climate zones are largely unresolved (Kolb, 2009; Kolb and Stacheter, 2013; Stacheter et al., 2013; Wohlfahrt et al., 2015).

Microbial methanol-utilizers were discovered in the late 19th century and can be aerobic or anaerobic (Loew, 1892; Chistoserdova et al., 2009; Kolb, 2009; Chistoserdova and Lidstrom, 2013; Hedderich and Withman, 2013). Aerobic methanol-utilizers are phylogenetically diverse and affiliate with gram-negative Alpha-, Beta-, and Gammaproteobacteria and Verrucomicrobia and with gram-positive Actinobacteria and Firmicutes, as well as with some fungi, i.e., ascomycetous yeasts and molds (Kolb, 2009; Gvozdev et al., 2012; Chistoserdova and Lidstrom, 2013; Kolb and Stacheter, 2013; Sharp et al., 2014).

Although methanol-utilizers were among the first microorganisms that were targeted in the environment using molecular tools two decades ago, an understanidng of their global biogeography has only just started to grow (Holmes et al., 1995; Kolb and Stacheter, 2013). The sensitivity of the environmental detection of low-abundant, one-carbon $\left(\mathrm{C}_{1}\right)$ compound converting microorganisms has been improved by the detection of key genes of methylotrophy (Holmes et al., 1995; McDonald and Murrell, 1997; Kolb and Stacheter, 2013). The initial enzymatic step of microbial methanol utilization is the oxidation of methanol to formaldehyde. For this reaction, at least three different enzymes occur in Bacteria (Kolb and Stacheter, 2013). In methylotrophic fungi, methanol is oxidized by alternative oxidoreductases (Gvozdev et al., 2012). The most prominent methanol oxidoreductase is the pyrroloquinoline quinone (PQQ)-dependent methanol dehydrogenase (MDH) encoded by the genes mxaFI. Burkholderiales possess an isoenzyme encoded by $m d h 2$ (Kalyuzhnaya et al., 2008). In many Bacteria, xoxF (synonymous to $m x a F^{\prime}$ ) is present, and a subtype (belonging to clade xoxF4) encodes a functional $\mathrm{MDH}$ that has been recently used to detect xoxF-possessing Bacteria in coastal environments (Chistoserdova, 2011; Taubert et al., 2015). Based on this broad spectrum of known enzymes, several gene markers have been developed. However, only $m x a F$ and xoxF are currently well-established functional gene markers that have been used in environmental surveys of methanol-utilizers, whereby no universal primers covering all five $x o x F$ clades exist (McDonald and Murrell, 1997; Moosvi et al., 2005; Neufeld et al., 2007; Stacheter et al., 2013; Taubert et al., 2015). Knowing the limitations of available functional markers, we complemented the detection of $m x a F / x o x F$ and bacterial 16S rRNA genes in combination with a stable isotope labeling apporach to identify methanol-utilizers in a forest soil.

The taxonomic diversity of methanol-utilizers in temperate forest soils is affected by soil $\mathrm{pH}$ and the presence of trees, but a detailed understanding of driving factors in these ecosystems is lacking (Kolb, 2009; Degelmann et al., 2010; Stacheter et al., 2013). Soil-derived methanol-utilizers often grow on multicarbon compounds (Kolb, 2009). Thus, one may speculate that such facultatively methylotrophic microorganisms might occupy different ecological niches with regard to their alternative substrates in the organic compound-rich top layer of forest soils, which would enable them to permanently establish in a complex soil community along with other methanol-utilizers and nonmethylotrophic heterotrophs.

Few studies have begun to gain a more detailed understanding of methanol-utilizers in soils (Radajewski et al., 2000, 2002; Lueders et al., 2004; Stacheter et al., 2013). The limited molecular detection based on gene markers in most of the previous studies on soil methylotrophs might have led to an underestimation of the taxonomic biodiversity of these methylotrophs. Thus, the current scientific view on terrestrial methanol-utilizers is still largely based on pure cultures and few stable isotope probing (SIP) experiments (Radajewski et al., 2002; Lueders et al., 2004; Kolb, 2009).

In our study, comparative DNA SIP experiments with several ${ }^{13} \mathrm{C}$-isotopologs of potential alternative multi-carbon substrates and with $\left[{ }^{13} \mathrm{C}_{1}\right]$-methanol in separate treatments were conducted in an acidic aerated forest soil. Thereby, we focussed on the substrate utilization of methanol-utilizing methylotrophs under mixed substrate conditions (i.e., the presence of methanol and an alternative $\left[{ }^{13} \mathrm{C}_{\mathrm{u}}\right]$-substrate). To better understand the role of soil $\mathrm{pH}$ for niche partitioning of detectable soil methanol-utilizers, we conducted a methanol-supplemented SIP experiment under the acidic in situ and artificially induced $\mathrm{pH}$-neutral conditions, at which most soil-derived isolates have their growth optimum. The specific objectives of this study were (i) to identify aerobic bacteria and fungi that assimilated methanol-derived carbon, (ii) to evaluate the significance of soil $\mathrm{pH}$ on indigenous methanolutilizers, and (iii) to resolve alternative substrate spectra of active methanol-utilizers using common soil organic compounds.

\section{MATERIALS AND METHODS}

\section{Study Site and Soil Sampling}

The study site was located in a temperate German forest (Steigerwald, $49^{\circ} 52^{\prime} \mathrm{N}, 10^{\circ} 28^{\prime} \mathrm{E}$ ) dominated by European beech (Fagus sylvatica). The characteristics of the soil are described elsewhere (Degelmann et al., 2009). Soil samples were taken from the upper part of the soil $(10 \mathrm{~cm}, \mathrm{O}$ plus A horizons) without the litter layer. Five sampling sites were chosen that reflected 
the general characteristics of the sampling area (saplings, dead wood, clearing, shady, and old beeches). Samples were taken in August 2013 (for the substrate SIP experiment) and in September 2014 (for the $\mathrm{pH}$ shift SIP experiment). Fresh forest soil samples were sieved $(2 \mathrm{~mm})$ and equally pooled to further prepare the soil slurries.

\section{$\left[{ }^{13} C_{u}\right]$-Substrates for SIP Experiments}

Filter-sterilized $40 \mathrm{mM}$ stock solutions of methanol and multicarbon substrates (i.e., acetate, glucose, xylose, and vanillic acid) were prepared with either the $\left[{ }^{13} \mathrm{C}\right]$-isotopolog ('labeled,' 99 atom\% $\mathrm{C}$ ) or the $\left[{ }^{12} \mathrm{C}\right]$-isotopolog (i.e., 'unlabeled, natural abundance of ${ }^{13} \mathrm{C}$ ). All multi-carbon substrate stock solutions also included $40 \mathrm{mM}\left[{ }^{12} \mathrm{C}\right]$-methanol. The isotopologs were fully labeled (i.e., $\left[{ }^{13} \mathrm{C}_{\mathrm{u}}\right]$ ) except for vanillic acid, in which only the aromatic ring carbon atoms were $\left[{ }^{13} \mathrm{C}\right]$-labeled (i.e., $\left.\left[{ }^{13} \mathrm{C}_{1-6}\right]\right) \cdot \mathrm{CO}_{2}$ treatments were set up with either $\left[{ }^{13} \mathrm{C}\right]-\mathrm{CO}_{2}$ ('labeled,' 99 atom $\% \mathrm{C}$; $<3$ atom $\%{ }^{18} \mathrm{O}$ ) or $\left[{ }^{12} \mathrm{C}\right]-\mathrm{CO}_{2}$. For more detailed information, refer to the Supplementary Information on Materials and Methods.

\section{Substrate SIP Experiment under Mixed Substrate Conditions}

Soil slurries were prepared by mixing $50 \mathrm{~g}$ of freshly sieved soil with $40 \mathrm{ml}$ of trace element solution (in $1 \mathrm{~L}$ of sterile water: $\mathrm{HCl}, 50 \mu \mathrm{M} ; \mathrm{FeCl}_{2}, 5 \mu \mathrm{M} ; \mathrm{ZnCl}_{2}, \mathrm{MnCl}_{2}, \mathrm{CoCl}_{2}, 50 \mu \mathrm{M}$; $\mathrm{Na}_{2} \mathrm{MoO}_{4}, 0.15 \mu \mathrm{M} ; \mathrm{H}_{3} \mathrm{BO}_{3}, \mathrm{NiCl}_{2}, 0.10 \mu \mathrm{M} ; \mathrm{CuCl}_{2}, 0.01 \mu \mathrm{M}$; after Whittenbury et al., 1970) and initially homogenized by hand shaking. Incubations were conducted as soil slurries to achieve homogenous physicochemical conditions (e.g., substrate concentrations, redox conditions, and $\mathrm{pH}$ ) and to provide a sufficent distribution of supplemented substrates as well as a balanced distribution of microorganisms to minimize heterogeneity in collected sub-samples.

Incubations were performed in duplicates for each approach (control, ${ }^{12} \mathrm{C}$, and ${ }^{13} \mathrm{C}$ ) on an end-over-end shaker at $20^{\circ} \mathrm{C}$ in the dark. Oxic conditions were maintained by placing a large gas phase inside the flasks (the ratio of gas phase to slurry volume was 12:1) and by daily opening for few minutes before re-sealing, allowing gas phase exchange. The $\mathrm{O}_{2}$ concentrations were monitored to ensure oxic conditions.

Substrates (i.e., methanol, acetate, and sugars; $1 \mathrm{ml}$ ) and methane were daily supplemented to a final concentration of $1 \mathrm{mM}$ and $200 \mathrm{ppm}$, respectively. Vanillic acid $(1 \mathrm{ml}, 1 \mathrm{mM}$ final concentration) was supplemented if it was no longer detected. In order to obtain mixed substrate conditions methanol $\left({ }^{12} \mathrm{C}\right)$ was supplemented in combination with alternative multi-carbon substrates $\left({ }^{12} \mathrm{C}\right.$ or $\left.{ }^{13} \mathrm{C}\right)$ at the same concentrations $(1 \mathrm{mM}$, final concentration). Thus, treatments solely supplemented with methanol served as multi-carbon substrate controls. Unsupplemented control treatments (i.e., solely $1 \mathrm{ml}$ trace element solution was supplemented) served as methanol control treatments and lacked any other substrate supplementation besides methane. Methane was supplemented to support also methanotrophic organisms in the soil, which might also be important methanol-utilizers (such as the methanotrophic
USC $\alpha$ group, Degelmann et al., 2010). $\mathrm{CO}_{2}$ incubations were supplemented with $10 \% \mathrm{CO}_{2}$ in the headspace (approximately $7 \mathrm{mM}$ total concentration) and opened if the $\mathrm{O}_{2}$ concentration was below $10 \%$. The purpose of the $\mathrm{CO}_{2}$ treatments was to evaluate the cross-feeding effects through the assimilation of $\left[{ }^{13} \mathrm{C}\right]-\mathrm{CO}_{2}$.

For more detailed information and an overview over the experimental set-up (Supplementary Figure S1), refer to the Supplementary Information on Materials and Methods.

\section{pH Shift SIP Experiment under Methylotrophic Conditions}

Two treatments were conducted, mimicking acidic in situ and elevated $\mathrm{pH}$-neutral conditions. Soil slurries were prepared according to the substrate SIP experiment. The treatments for in situ $\mathrm{pH} 4$ were prepared by mixing $50 \mathrm{~g}$ freshly sieved soil and $40 \mathrm{ml}$ of trace element solution in one incubation flask. The treatments for $\mathrm{pH} 7$ were prepared by mixing $300 \mathrm{~g}$ freshly sieved soil with $240 \mathrm{ml}$ of trace element solution. Then, the $\mathrm{pH}$ was adjusted to 7 with sterile $\mathrm{NaOH}$, and the solution was mixed until the $\mathrm{pH}$ remained constant. A total of $90 \mathrm{ml}$ of the $\mathrm{pH}$ adjusted slurry (corresponding with the volume of a slurry consisting of $50 \mathrm{~g}$ soil and $40 \mathrm{ml}$ trace element solution) was placed into each incubation flask. Methanol was supplemented daily to a final concentration of $1 \mathrm{mM}$ per pulse. Control treatments were only supplemented with the same volume of trace element solution. Daily aliquots were taken, and the $\mathrm{pH}$ was monitored to avoid changes and re-adjusted when necessary. The $\mathrm{pH}$ shift SIP experiment treatments lacked methane supplementation. Thus, a putatively supporting effect of methane on methylotrophs under in situ conditions could be evaluated by the comparison of all methanol treatments of both SIP experiments conducted, i.e., substrate SIP and $\mathrm{pH}$ shift SIP experiment. For more detailed information, refer to the Supplementary Information on Materials and Methods.

\section{Chemical Analytics}

The $\mathrm{pH}$ value was determined in soil slurry aliquots. Gases were measured by gas chromatography using thermal conductivity $\left(\mathrm{O}_{2}, \mathrm{CO}_{2}\right)$ and a flame ionization detector (methane). The amount of $\left[{ }^{13} \mathrm{C}\right]-\mathrm{CO}_{2}$ was determined using GC mass spectrometry. The conversion of supplemented multi-carbon compounds was monitored by high-performance liquid chromatography (HPLC) using the refractive index and a diode array detector. Details can be found in the Supplementary Information on Materials and Methods.

\section{Nucleic Acid Extraction and Separation of 'Heavy' (H), 'Middle' (M), and 'Light' (L) DNA by Density Gradient Centrifugation}

Nucleic acids were extracted from two $0.5 \mathrm{~g}$ soil slurry samples of each replicate according to Griffiths et al. (2000). DNA was precipitated, purified from co-extracted RNA by RNase treatment and quantified with Quant-iT-Pico Green (Invitrogen, Carlsbad, CA, United States). 
DNA SIP was performed according to the protocol of Neufeld et al. (2007). Equally pooled DNA from the $\mathrm{t}_{0},{ }^{12} \mathrm{C}$ and ${ }^{13} \mathrm{C}$ treatments $(5-10 \mu \mathrm{g})$ was added to $\mathrm{CsCl}$-containing gradients [buoyant density (BD) $1.732 \pm 0.0006 \mathrm{~g} \mathrm{ml}^{-1}$ ]. Isopycnic centrifugation was performed (44 $100 \mathrm{rpm}$, i.e., $177000 \mathrm{gav}_{\mathrm{av}}$, at $20^{\circ} \mathrm{C}$ for $40 \mathrm{~h}$; rotor VTi65.2; Beckmann, Fullerton, CA, United States) to separate DNA by its BDs. Gradients were separated into 10 fractions ( $450 \mu \mathrm{l}$ each), and the BD of each fraction was determined by repeated weighing at $20^{\circ} \mathrm{C}$. DNA was precipitated with glycogen $\left(10 \mathrm{mg} \mathrm{ml}^{-1}\right)$ and polyethylene glycol and quantified.

According to the reported $\mathrm{BD}$ for non-labeled and fully labeled DNA (Lueders et al., 2004), fractions 1 to 10 were separately pooled into 'heavy' $(\mathrm{H})$ fractions $\left(\mathrm{BD} \geq 1.730 \mathrm{~g} \mathrm{ml}^{-1}\right)$, 'middle' (M) fractions (BD between 1.730 and $1.715 \mathrm{~g} \mathrm{ml}^{-1}$ ), and 'light' (L) fractions $\left(\mathrm{BD} \leq 1.715 \mathrm{~g} \mathrm{ml}^{-1}\right)$.

\section{Barcoded Amplicon Pyrosequencing of 16S rRNA Genes, mxaF/xoxF, and ITS}

DNA from the pooled fractions was used for amplicon pyrosequencing. For bacterial genes (i.e., 16S rRNA and $m x a F / x o x F)$, a two-step PCR approach was performed to decrease bias (Berry et al., 2011). In brief, amplicons derived from a first PCR with 'conventional' primers (i.e., untagged primers) were subsequently amplified with 'barcoded' primers (i.e., primers with an additional barcode sequences at the $5^{\prime}$ terminus) to obtain amplicons with distinguishable nucleotide tags (details in Supplementary Information on Materials and Methods).

Bacterial 16S rRNA gene fragments were amplified using the primers $341 \mathrm{f}$ and $785-805 \mathrm{r}$, which had the best overall bacterial sequence and phylum coverage (Muyzer et al., 1998; Herlemann et al., 2011; Klindworth et al., 2013). In order to amplify $m x a F / x o x F$ gene sequences the primer pairs ' $m x a F 1$ ' (1003f/1555r; McDonald and Murrell, 1997; Neufeld et al., 2007) and ' $m x a F 2$ ' (mxaF_for/mxaF_rev; Moosvi et al., 2005) were used. Simultaneous amplification of $m x a F$ and $x o x F$ is assumed since in a previous study $x o x F$ gene sequences were also amplified using the primer pair 'mxaF1' (Stacheter et al., 2013). Trials to amplify pmoA (encodes the beta-subunit of particulate methane monooxygenase) genes were not sufficiently successful, i.e., only a sparse smear or weak bands were visible after PCR and purification led to loss of amplicons. Thus, this gene was no longer analyzed. Barcoded amplicon pools were pyrosequenced at the Göttingen Genomics Laboratory using a Roche GSFLX 454 Sequencer and GSL FLX Titanium series reagents (Roche Diagnostics GmbH, Mannheim, Germany) as previously described (Stacheter et al., 2013). Fungal ITS fragments (internal transcibed spacer) were amplified using the primers ITS1F and ITS4 (White et al., 1990; Gardes and Bruns, 1993). The amplicons obtained were equimolarly pooled and pyrosequenced at the Department of Soil Ecology (UFZ, Halle, Germany) as previously described (Wubet et al., 2012). For detailed information on the primer sequences, PCR conditions, strategies and performance, please refer to the Supplementary Information on Materials and Methods.

\section{Read Filtering and Clustering}

The reads of bacterial genes were trimmed to nearly equal sequence lengths (446 bp for 16S rRNA, 440 bp for mxaF), amplicon pyrosequencing errors were corrected using ACACIA, and potential 16S rRNA chimeric sequences were sorted out using the UCHIME algorithm implemented in USEARCH and the latest RDP Gold database for high-quality 16S rRNA gene reference sequences (Edgar et al., 2011; Bragg et al., 2012). Using JAguc v2.1, the sequences were clustered into operational taxonomic units (OTUs) applying the UPGMA model (Nebel et al., 2011). The OTUs of $16 \mathrm{~S}$ rRNA were clustered at the family level using $90.1 \%$ as the pairwise similarity cut-off value (to ensure sufficient sampling depth), and mxaF OTUs were clustered with a cut-off value of $90 \%$, which was higher than that previously reported, to obtain a higher diversity (Yarza et al., 2010; Stacheter et al., 2013). Representative sequences (i.e., longest sequence, in the case of identical lengths the sequence was randomly chosen by the program) of each OTU were used for further taxonomic affiliation. 16S rRNA phylotypes were primarily affiliated using a local nucleotide BLAST and affiliation was checked by a online megaBLAST that uses a nucelotide database updated daily and a phylogenetic tree generated using MEGA Version 6.06 (Tamura et al., 2013). The phylogenetic affiliation of mxaF phylotypes was determined using manual BLAST (megaBLAST) and phylogenetic treeing.

For the detailed resolution of $\mathrm{OTU}_{165} 438$ the filtered $16 \mathrm{~S}$ rRNA gene dataset (also used in the JAguc analysis) and all sequences of $\mathrm{OTU}_{16 \mathrm{~S}} 438$ were combined and clustered using QIIME at a species-level cut-off. For more detailed information refer to the Supplementary Information on Materials and Methods.

Reads of fungal ITS genes were demultiplexed and quality trimmed using MOTHUR, normalized (1503 counts per sample), and checked for chimeric sequences using UCHIME (Schloss et al., 2009; Edgar et al., 2011). The sequences were clustered into OTUs using CD-HIT-EST at a 97\% pairwise similarity cut-off value (Fu et al., 2012). Representative sequences were classified against the dynamic UNITE database (v7 release 01.08.2015; Kõljalg et al., 2013) using a MOTHUR-implemented classifier of Wang et al. (2007). For detailed information, please refer to the Supplementary Information on Materials and Methods.

\section{Identification of ' ${ }^{13} \mathrm{C}$-Labeled' Phylotypes}

The ${ }^{~} 13$ C-label' of phylotypes was determined by analyzing the relative abundances of phylotypes in the amplicon read libraries of the $\mathrm{H}, \mathrm{M}$, and $\mathrm{L}$ fractions of the $\left[{ }^{12} \mathrm{C}\right]$ and $\left[{ }^{13} \mathrm{C}\right]$ treatments of each gene dataset (i.e., $16 \mathrm{~S}$ rRNA gene, mxaF, and ITS). The phylotypes that occurred only once within the complete dataset of all amplicon libraries were considered erroneous and removed, whereas singletons in each individual amplicon library were preserved (not applied for the ITS dataset, in which phylotypes with fewer than three reads were removed in the previous readfiltering step). A comparison of the relative abundances in the $\mathrm{H}$ fractions of $\left[{ }^{13} \mathrm{C}\right]$ treatments with those in the $\mathrm{H}$ fractions of $\left[{ }^{12} \mathrm{C}\right]$ treatments and a comparison of the $\mathrm{H}$ and $\mathrm{L}$ fractions of the 
$\left[{ }^{13} \mathrm{C}\right]$ treatment were conducted. This procedure minimizes the identification of false-positive phylotypes due to the migration of light DNA into the $\mathrm{H}$ fractions (Lueders et al., 2004; Dallinger and Horn, 2014). The following criteria had to be met to classify a phylotype as 'labeled': (1) The abundance in the appropriate fraction (i.e., $\mathrm{H}$ or $\mathrm{M}$ fraction) of the $\left[{ }^{13} \mathrm{C}\right]$ treatment was higher than that in the corresponding fraction of the $\left[{ }^{12} \mathrm{C}\right]$ treatment; (2) the abundance in the $\mathrm{L}$ fraction was lower than that in the $\mathrm{H}$ or $\mathrm{M}$ fraction of the $\left[{ }^{13} \mathrm{C}\right]$ treatment; (3) the abundance in the $\mathrm{H}$ or $\mathrm{M}$ fraction of the $\left[{ }^{13} \mathrm{C}\right]$ treatment was $\geq 0.5 \%$; and (4) the difference in the abundance in the compared fractions of the $\left[{ }^{13} \mathrm{C}\right]$ treatment was $\geq 0.1 \%$ compared to that of the $\left[{ }^{12} \mathrm{C}\right]$ treatment. Phylotypes that met all these criteria were considered 'potentially labeled' and were the basis for the calculation of the 'labeling proportion' (LP). The LP serves as an indicator for the relative importance of different bacterial taxa assimilating the supplemented $\left[{ }^{13} \mathrm{C}_{\mathrm{u}}\right]$-substrate (directly or indirectly) and is not a proxy for the amount of incorporated ${ }^{13} \mathrm{C}$ into the DNA. The LP of a certain potentially labeled phylotype $\mathrm{x}$ was

$$
\mathrm{LP}_{\mathrm{x}}=\frac{100}{\sum_{\mathrm{i}=1}^{\mathrm{n}} \mathrm{RA}_{\mathrm{i}}^{13 \mathrm{C}}} \times \mathrm{RA}_{\mathrm{x}}^{13 \mathrm{C}}
$$

with $\mathrm{RA}$ is the relative abundance, $\mathrm{n}$ is the number of all 'potentially labeled' phylotypes, $\sum_{i=1}^{n} R_{i}^{13 C}$ is the sum of all relative abundances of 'potentially labeled' taxa in the $\mathrm{M}$ or $\mathrm{H}$ gradient fraction of the $\left[{ }^{13} \mathrm{C}\right]$ treatment, and $\mathrm{RA}_{\mathrm{x}}^{13 \mathrm{C}}$ is the relative abundance of a certain phylotype $\mathrm{x}$ in the $\mathrm{M}$ or $\mathrm{H}$ gradient fraction of the $\left[{ }^{13} \mathrm{C}\right]$ treatment. A threshold value of $5 \%$ was used to distinguish between labeled taxa of greater (i.e., $\mathrm{LP}_{\mathrm{x}} \geq 5 \%$ ) or minor (i.e., $\mathrm{LP}_{\mathrm{x}}<5 \%$ ) importance (Dallinger and Horn, 2014). The phylotypes that were identified as labeled in the $M$ fraction were considered as 'weakly labeled' for two possible reasons: (i) not fully labeled DNA and (ii) fully labeled DNA of organisms with very low GC content $(<40 \%)$. Nonetheless, we expected that the general genome GC content is higher than $40 \%$ and is similar for the majority of microorganisms of this environment as previous genome studies suggest (Foerstner et al., 2005).

\section{Quantification of 16S rRNA Genes, $m x a F$, and $m m o X$ in the pH Shift SIP Experiment}

The gene fragments were quantified in duplicates on an iQ5 Real-Time qPCR cycler (BioRad, Munich, Germany) with primer sets specific for Bacteria and mxaF (Moosvi et al., 2005) and $m m o X$ (Kolb et al., 2005) using internal standards. According to published protocols, all qPCR measurements were inhibitor corrected because co-extracted humic acids were obvious and inhibition was well-recorded (Degelmann et al., 2010; Zaprasis et al., 2010) (detailed information in Supplementary Information on Materials and Methods).

\section{Nucleotide Sequence Accession Numbers}

Representative sequences of labeled phylotypes derived from barcoded amplicon pyrosequencing were deposited in EMBL under accession numbers LT607885 to LT607955 (16S rRNA gene), LT607956 to LT608017 (mxaF), and LT608018 to LT608119 (ITS). All raw pyrosequencing datasets were deposited in the ENA Short Read Archive under the study accession number ERP016444, including the 16S rRNA gene, $m x a F$ and ITS datasets.

\section{RESULTS}

\section{Identification of Microorganisms Utilizing Methanol-Derived Carbon in an Acidic Forest Soil}

A successful labeling of Bacteria and fungi was proven by the dissimilar composition of phylotypes of $\left[{ }^{12} \mathrm{C}\right]$ and $\left[{ }^{13} \mathrm{C}\right] \mathrm{H}$ and $\mathrm{M}$ fractions (Supplementary Figure S1). In addition, the carbon recovery rates for $\left[{ }^{13} \mathrm{C}\right]-\mathrm{CO}_{2}$ revealed that the supplemented substrates were not only dissimilated but were also assimilated (Supplementary Figures S3, S4).

The $\left[{ }^{13} \mathrm{C}_{1}\right]$-methanol treatment of the substrate SIP experiment revealed one labeled phylotype (OTU $\left.{ }_{16 S} 438\right)$ dominating the $\mathrm{H}$ fraction. This phylotype was also highly labeled in the $\mathrm{M}$ fraction and was affiliated to Beijerinckiaceae, i.e., it was closely related to methylotrophic species such as Methylovirgula ligni (Figure 1A and Supplementary Tables S1, S2). Further minor and weakly labeled phylotypes were found among a wide range of bacterial phyla (i.e., minor labeled, LP $<2 \%$ : Acidobacteria, Proteobacteria, and Verrucomicrobia; weakly labeled: Armatimonadetes, Planctomycetes, Alphaproteobacteria, and Verrucomicrobia) (Figure 1A and Supplementary Table S1). The sequence identities of these labeled phylotypes to their closest related cultured species ranged from 83 to 99\% (Supplementary Table S2), suggesting that hitherto unrecognized methanol-utilizers or methanol-derived carbon-utilizers occurred.

The $\left[{ }^{13} \mathrm{C}_{1}\right]$-methanol treatment of the $\mathrm{pH}$ shift SIP experiment revealed a slightly different distribution of labeled phylotypes compared to the substrate SIP experiment suggesting an influence of methane on the methanol-utilizer community in the forest soil. In addition to the Beijerinckiaceae-phylotype (OTU $\left.{ }_{16 \mathrm{~S}} 438\right)$, also phylotypes affiliated to Microbacteriaceae (OTU $165721,99 \%$ sequence identity to Leifsonia xyli) and Chitinophagaceae (OTU $16 \mathrm{~S} 1020,96 \%$ sequence identity to Chitinophaga sp.) were labeled (Figure 1C and Supplementary Table S6). Further minor or weakly labeled phylotypes belonged to Sphingobacteriales, Paenibacillaceae, Sphingomonadaceae, and Xanthomonadaceae (Rhodanobacter) (Figure 1C and Supplementary Table S6).

\section{Labeled Phylotypes Based on MDH Gene Markers}

The specific primers used in our study were assumed to target $m x a F$ as well as $x o x F$ gene sequences as a previous study on temperate soils indicated (Stacheter et al., 2013). However, no $x o x F$-affiliated phylotype was labeled in any treatment (including also $\left[{ }^{13} \mathrm{C}_{\mathrm{u}}\right]$-substrate treatments of the substrate SIP experiment), 


\section{A}
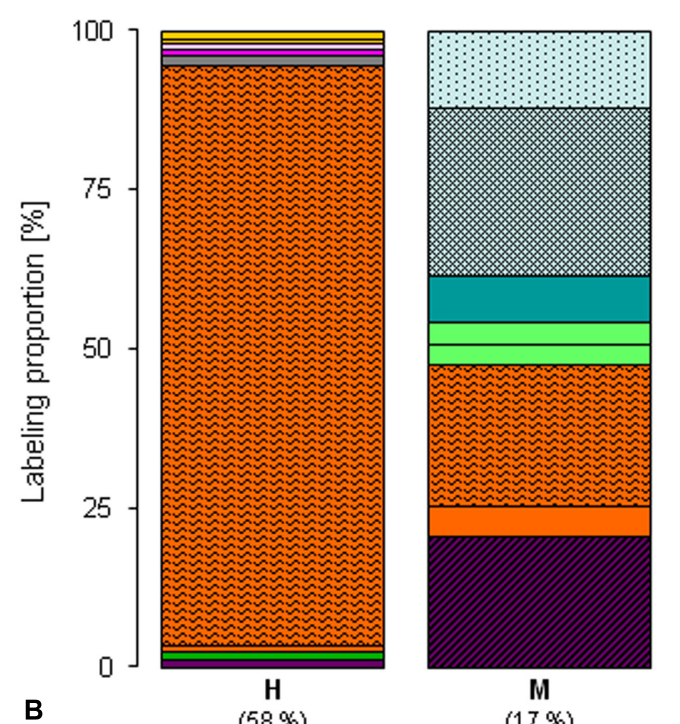

C

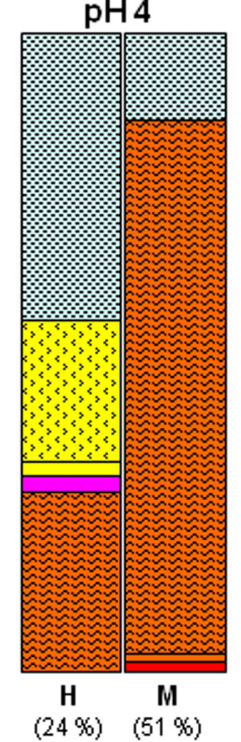

$(17 \%$
$\mathrm{pH} 7$

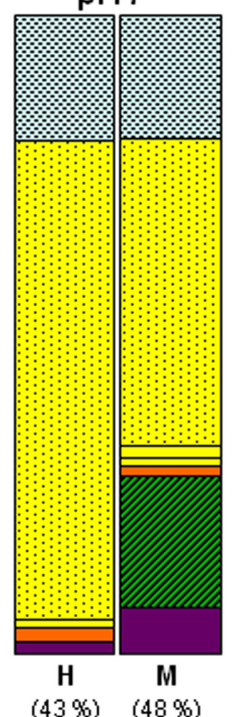

(43\%) (48\%)
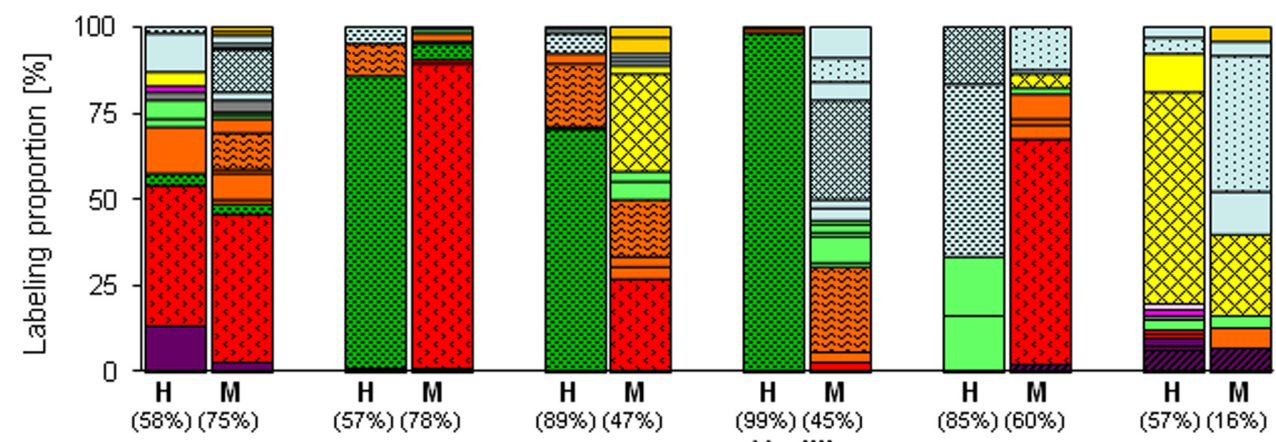

Acetate +

Glucose +

Xylose+

Vanillic
Acidobacteriaceae
Actinobacteriaceae
Acidimicrobiaceae (0TU $\left.\mathrm{O}_{16 \mathrm{~S}} 652\right)$
Kineosporiaceae (OTU $\left.\mathrm{OTS}_{163} 703\right)$
Microbacteriaceae $\left(\mathrm{OTU}_{16 \mathrm{~S}} 721\right)$
Armatimonadetes
Bacteroidetes
Chitinophagaceae (OTU $16 \mathrm{1020}$ )
Flavobacteriaceae (OTU 165 1045)
X Sphingobacteriaceae (OTU $16 \mathrm{1073}$ )

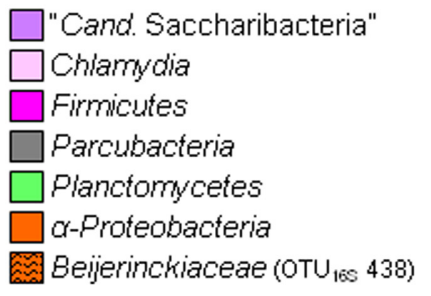

$\mathrm{CO}_{2}+$

$\mathrm{CO}_{2}$

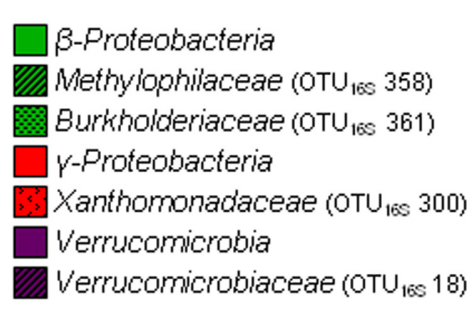

FIGURE 1 | Labeling proportions (LPS) and identities of bacterial $16 \mathrm{~S}$ rRNA phylotypes in the 'heavy' and 'middle' fractions of [ $\left.{ }^{13} \mathrm{C}_{1}\right]$-methanol (A) and $\left[{ }^{13} \mathrm{C}_{\mathrm{u}}\right]$-substrates $\mathbf{B}$ ) treatments of the substrate SIP experiment, and treatments of the pH SIP experiment (C). Cross, additional [ $\left.{ }^{12} \mathrm{C}\right]$-methanol supplementation in substrate treatments. Equal colors, the same phylum affiliation. ' $H$ ' and 'M,' 'heavy' and 'middle' fractions, respectively. Values in brackets, contribution of labeled phylotypes to the total number of sequences. The 'labeling proportions' are indicators for the relative importance of different taxa assimilating the supplemented ${ }^{13} \mathrm{C}$ (directly or indirectly). More detailed taxonomic information can be found in Supplementary Tables S16, S17.

and potentially further present xoxF-containing methylotrophs might have been overlooked. The labeled phylotypes of the $\left[{ }^{13} \mathrm{C}_{1}\right]$-methanol treatment of the substrate SIP experiment were dominated by three phylotypes belonging to Methylobacterium $\left(\mathrm{OTU}_{\mathrm{mxaF}} 40\right)$ and Hyphomicrobium (OTUs $\mathrm{mxaF}_{185}$ and 210), whereas in the $\left[{ }^{13} \mathrm{C}_{1}\right]$-methanol treatment of the $\mathrm{pH}$ shift
SIP experiment labeled mxaF phyloytpes belonged mainly to Hyphomicrobium.

Although Beijerinckiaceae appeared to be the dominantly labeled bacterial phylotype based on the 16S rRNA genes, only one Beijerinckiaceae-related mxaF phylotype (OTU $\mathrm{mxaF}_{144)}$ was labeled in the substrate SIP experiment (Supplementary 


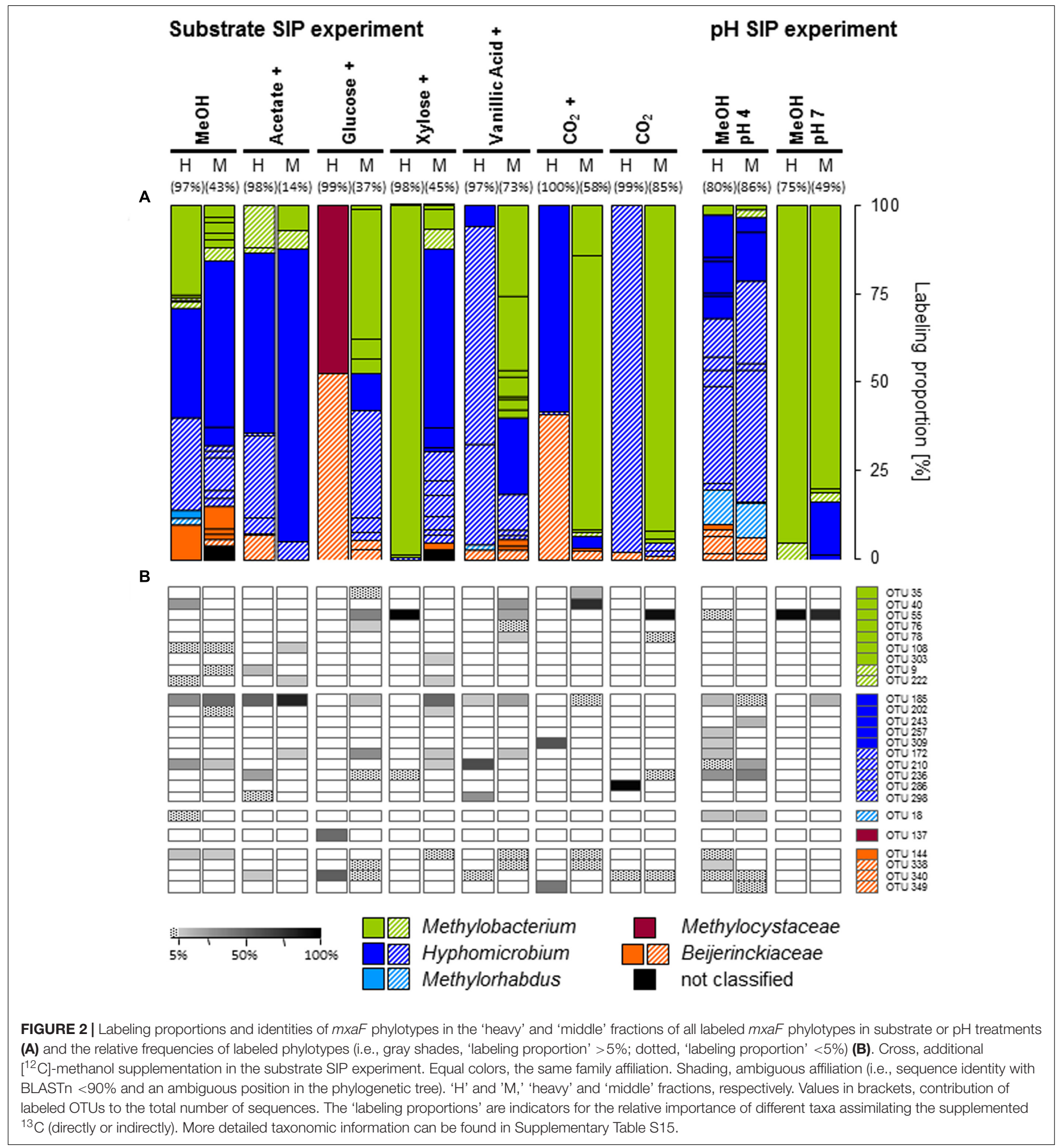

Table S3 and Figure 2A). Methane might have stimulated this mxaF-phylotype since its LP was lower in the methanefree treatment of the $\mathrm{pH}$ shift SIP experiment. In this treatment another Beijerinckiaceae-phylotype $\left(\mathrm{OTU}_{\mathrm{mxaF}}{ }^{338}\right)$ and a Methylorhabdus-affiliated phylotype $\left(\mathrm{OTU}_{\mathrm{mxaF}} 18\right)$ were weakly labeled (Figure 2A and Supplementary Table S8, Figures S5-S7, S9).

\section{Fungi Assimilating Methanol-Derived Carbon}

Apart from Bacteria also fungi assimilated methanolderived carbon (Figure 3A and Supplementary Table S4). In the $\left[{ }^{13} \mathrm{C}_{1}\right]$-methanol treatment of the substrate SIP experiment, one abundantly labeled phylotype was affiliated to the basidiomycetous yeast Cryptococcus 

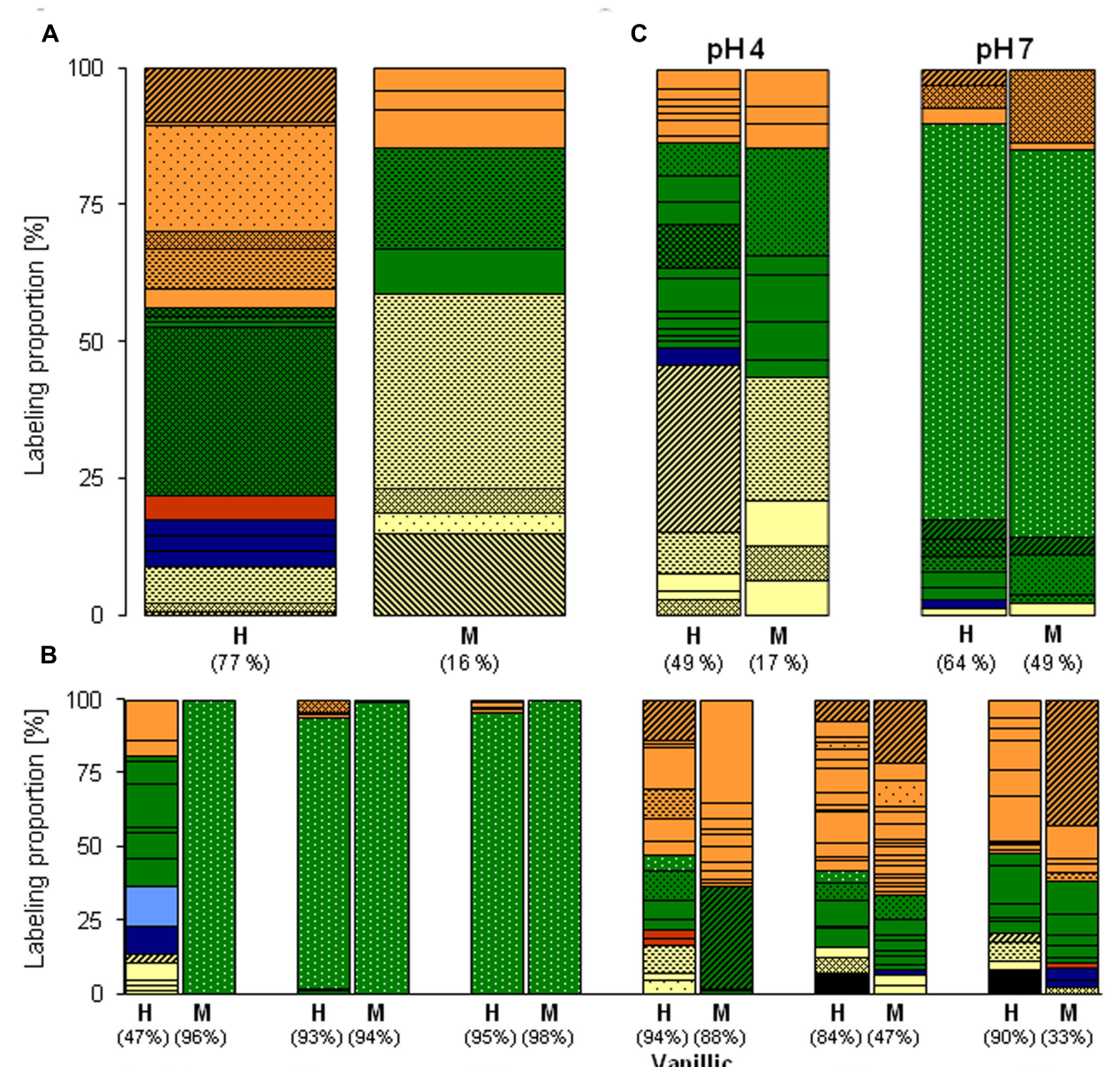

Acetate +

Glucose +

Xylose+

Vanillic
Acid +

$\mathrm{CO}_{2}+$

$\mathrm{CO}_{2}$

Ascomycota

Saccharomycetes (OTU $\left.\mathrm{ms}^{2}\right)$

Penicilium (OTU $\mathrm{ms}^{10}$ )

Paecilomyces (OTU $\mathrm{ms}^{14)}$

Oidiodendron ( $\left.\mathrm{OTU}_{\mathrm{ms}} 32\right)$

Chytridiomycota

Glomeromycota

Rozellomycota
Basidiomycota

Trichosporon (OTU $\mathrm{ms}_{1}$ )

Traptococcus $1(\mathrm{OTU}$ חs 6$)$

- Ganoderma (OTU $\mathrm{ms}^{7}$ )

Leucosporidiales (OTU ${ }_{\mathrm{ms}} 15$ )

Syzygospora (OTU $\mathrm{ms}^{22}$ )

Cryptococcus $2\left(\mathrm{OTU}_{\mathrm{ms}} 46\right)$



$\square$ Zygomycota

Wh Mortierella 1 (OTU ${ }_{\text {ms }}$ )

Mortierella $2\left(\mathrm{OTU} \mathrm{ms}^{5}\right)$

Mortierella 3 (OTU ms $^{33}$ )

not classified

FIGURE 3 | Labeling proportions and identities of fungal ITS phylotypes in the 'heavy' and 'middle' fractions of $\left[{ }^{13} \mathrm{C}_{1}\right]$-methanol (A) and different $\left[{ }^{13} \mathrm{C}_{\mathrm{u}}\right]$-substrates (B) treatments of the substrate SIP experiment, and of the treatments of the pH SIP experiment (C). Cross, additional $\left[{ }^{12} \mathrm{C}\right]$-methanol supplementation in substrate treatments. Equal colors, the same phylum affiliation. 'H' and 'M,' 'heavy' and 'middle' fractions, respectively. Values in brackets, contribution of labeled OTUs to the total number of sequences. The 'labeling proportions' are indicators for the relative importance of different taxa assimilating the supplemented ${ }^{13} \mathrm{C}$ (directly or indirectly).

(OTU ITS $\left._{46}\right)$. Further labeled phylotypes $(\mathrm{LP} \geq 5 \%)$ were affiliated to Ascomycota (OTUs ITS $_{10}$, 32, and 2) and Zygomycota (OTU ITS5; Mortierella sp., $98 \%$ sequence identity) (Figure $\mathbf{3 A}$ and Supplementary Tables S4, S5). A weak label was observed for phylotypes affiliated to Zygomycota (OTU ITS 112), Basidiomycota (OTUs ITS $_{22}$ and 27), and Ascomycota (OTU ITS 135) (Figure $\mathbf{3 A}$ and Supplementary Tables S4, S5). Consistently with the $\left[{ }^{13} \mathrm{C}_{1}\right]$ methanol treatment of the substrate SIP experiment, the zygomycetous phylotypes of the $\left[{ }^{13} \mathrm{C}_{1}\right]$-methanol treatment of the $\mathrm{pH}$ shift SIP experiment were affiliated to the genus Mortierella (Figure 3C and Supplementary Tables S5, S10). In contrast, further labeled fungal phylotypes were affiliated to Basidiomycota (OTUs ITS $_{30}$, 15, 12, and 7) (Figure 3C and Supplementary Table S10), and a remarkable number of weakly labeled phylotypes were affiliated to Ascomycota, Basidiomycota, and Zygomycota (Figure 3C and Supplementary Table S10). 


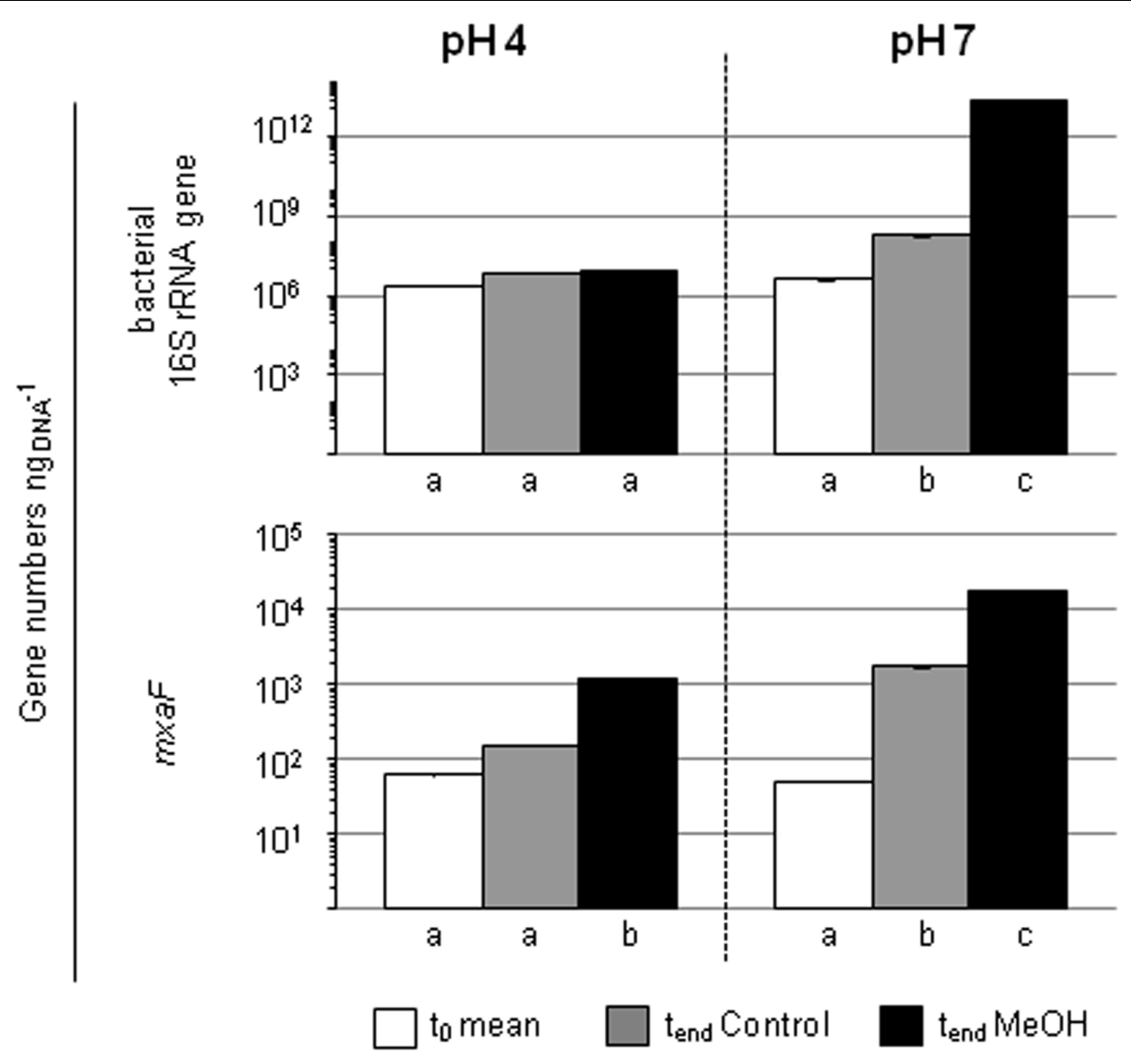

FIGURE 4 | Gene numbers of $16 \mathrm{~S}$ rRNA genes and $m x a F$ of treatments with different $\mathrm{pH}$ in the pH shift SIP experiment. Columns, mean values of the experimental replicates. Error bars, standard deviation; if not visible, the variability between replicates was below $0.5 \%$. Different letters, significant differences between samples ( $t$-test; normal distribution was assumed based on the Shapiro-Wilk-test; $n=3$ ).

\section{Effect of $\mathrm{pH}$ on the Abundance of Bacteria and Methylotrophs}

The quantification of the bacterial abundance (16S rRNA gene numbers) and mxaF gene numbers revealed an increase in both pH 7 treatments (i.e., the unsupplemented controls and methanol treatments), demonstrating the general growth restrictions at the in situ $\mathrm{pH} 4$ for Bacteria and methylotrophs (Figure 4). However, a decrease of $m m o X$ gene numbers in the $\mathrm{pH} 7$ treatment occurred, whereas the values remained constant in the $\mathrm{pH} 4$ treatments (Supplementary Figure S2) suggesting that the acidic in situ $\mathrm{pH}$ conditions were advantageous for methane-utilizing Beijerinckiaceae. Since the amplicons were not checked for their identity, a detection of non-target sequences cannot be excluded and thus this result should be regarded with caution.

\section{Identification of Autochthonous Microorganisms that Utilized Methanol-Derived Carbon under Elevated pH Conditions}

As expected several different phylotypes were labeled under the elevated $\mathrm{pH}$ condition indicating again the growth restricting conditions of the in situ acidic soil. In accordance with a generally increasing proportion of Bacteroidetes (Supplementary Figure S3A) in the pH 7 treatment, the most abundantly labeled phylotypes affiliated with Flavobacteriaceae (OTU $16 \mathrm{~S} 1045$, 99\% sequence identity to Chryseobacterium sp.) and Microbacteriaceae $\left(\mathrm{OTU}_{16 \mathrm{~S}} 721,99 \%\right.$ sequence identity to Leifsonia xyli) (Figure 1C and Supplementary Tables S2, S7). Weakly labeled phylotypes (i.e., LP < 3\%) were affiliated to Sphingobacteriaceae, Caulobacteraceae, and Verrucomicrobia with partially low sequence identities to the next related sequence of a cultured isolate (Supplementary Table S2). A Methylophilaceae-related phylotype $\left(\mathrm{OTU}_{16 \mathrm{~S}} 358\right)$ was only weakly labeled but with a high LP of approximately $20 \%$ (Figure 1C and Supplementary Tables S2, S7). This phylotype was not labeled in the $\mathrm{pH} 4$ treatment (Figures 1A,C), which suggests a decreased competitiveness and initial low abundance under in situ conditions. Further weakly labeled phylotypes were affiliated with Bacteroidetes, Alphaproteobacteria, and Verrucomicrobia (Figure 1C and Supplementary Tables S2, S7, Figure S10).

In contrast to the aforementioned findings on labeled $m x a F$ phylotypes, a Methylobacterium-related phylotype (OTU $\mathrm{mxaF}^{55)}$ 
was highly abundant indicating the preference of neutral $\mathrm{pH}$ conditions (Figure 2A and Supplementary Table S9).

A preference of a neutral $\mathrm{pH}$ was also observed for one fungal phylotype affiliated to the yeast Trichosporon (OTU $\mathrm{ITS}_{1} 1$ ), that was abundantly labeled under an elevated $\mathrm{pH}$. Further weakly labeled fungal phylotypes were affiliated to Ascomycota and Basidiomycota (Figure 3C and Supplementary Table S11), which suggests that these taxa did not play a dominant role in methanol assimilation.

\section{The Substrate Range of Methanol-Derived Carbon-Utilizing Microorganisms}

As expected, several taxa not known to include methylotrophs such as Xanthomonadaceae (OTU $16 \mathrm{~s} 300$, Rhodanobacter), Burkholderiaceae (OTU $16 \mathrm{~S} 361, \quad$ Burkholderia), and Sphingobacteriaceae (OTU ${ }_{16 \mathrm{~S}} 1073$, Mucilaginibacter) were labeled in the multi-carbon substrate treatments. If these microorganisms dissimilated methanol without assimilating carbon remains speculative. 'True' methanol and/or methanolderived carbon utilizers (i.e., assimilation of carbon from methanol) were identified in the $\left[{ }^{13} \mathrm{C}_{1}\right]$-methanol treatment. The congruent detection of a phylotype in both, the methanol and an alternative substrate treatment, was considered to estimate the putative substrate range of methanol-derived carbon utilizers.

The Beijerinckiaceae-phylotype (OTU $\left.{ }_{165} 438\right)$ was labeled in all treatments with multi-carbon compounds, which suggests that this phylotype assimilates carbon derived from acetate, sugars and even aromatic compounds in the presence of methanol (Figure 5). A more detailed analysis on specieslevel revealed that several phylotypes were grouped together by $\mathrm{OTU}_{16 \mathrm{~S}} 438$ and that clearly different trophic types belonged to this OTU (Figure 6). Species-level phylotypes that were identified as obligately methylotrophic (A, B, and D) were closely affiliated with known methylotrophs of Beijerinckiaceae (i.e., Methylorosula, Methyloferula, and Methylovirgula) and Hyphomicrobiaceae (i.e., Hyphomicrobium). Phylotype C was identified as restricted facultatively methylotrophic and was closely affiliated with Methylocella. Further phylotypes (E, F, G, $\mathrm{H}$, and I) were affiliated with several members of Rhizobiales but were apparently non-methylotrophic. Low LPs and sometimes only a weak labeling of the Beijerinckiaceae-affiliated phylotype (family-level) suggested a higher competition or slower growth rates with multi-carbon substrates. A potentially occuring crossfeeding via the assimilation of ${ }^{13} \mathrm{CO}_{2}$ can be considered as negligible because $\mathrm{OTU}_{16 \mathrm{~S}} 438$ was not labeled in the ${ }^{13} \mathrm{CO}_{2}$ treatments (Figures 1B, 5). However, the utilization of methanol cannot fully be excluded for the apparent nonmethylotrophic phylotypes since SIP analysis cannot resolve the sole dissimilation of methanol or the indirect carbon assimilation via $\mathrm{CO}_{2}$.

Further alphaproteobacterial methanol-derived carbonassimilating phylotypes exhibited both a broad substrate range (OTU ${ }_{16 S} 449 ;$ Sphingomonadaceae) and a narrow substrate range $\left(\mathrm{OTU}_{16 \mathrm{~S}} 467\right.$; Acetobacteraceae) (Figure 5). Interestingly, most of the $16 \mathrm{~S}$ rRNA phylotypes that were only labeled in the $\mathrm{pH} 7$ treatment were not labeled at the acidic in situ $\mathrm{pH}$ (Figure 5) suggesting an inhibition or even growth-restriction and thus no utilization of any multi-carbon substrate. Only the Microbacteriaceae-phylotype (OTU $16 \mathrm{~S} 721$, Leifsonia spp.) exhibited a broad substrate and $\mathrm{pH}$ range (Figure 5).

All mxaF phylotypes that were labeled in the methanol treatment of the substrate SIP experiment were also labeled in the multi-carbon substrate treatments (Figure $\mathbf{2 B}$ and Supplementary Table S3). A Hyphomicrobium-phylotype $\left(\mathrm{OTU}_{\mathrm{mxaF}} 185\right)$ exhibited the broadest substrate range and was detectable in all treatments supplemented with methanol $\left({ }^{12} \mathrm{C}\right.$ and $\left.{ }^{13} \mathrm{C}\right)$. A labeling in both the acetate and vanillic acid treatments was observed with high LPs for acetate indicating a preference for this substrate (Figure 2B). The weak labeling in both sugar treatments suggested a low carbon assimilation rate and/or a general higher competitive pressure through non-methylotrophic heterotrophs (Figure 2B). OTU mxaF 185 was also labeled in the $\mathrm{pH}$ shift SIP experiment, but a weaker labeling at $\mathrm{pH} 7$ indicated a preference for acidic conditions (Figure 2B and Supplementary Tables S8, S9). The weak labeling of a Beijerinckiaceae-phylotype $\left(\mathrm{OTU}_{\mathrm{mxaF}} 144\right)$ in treatments containing xylose, vanillic acid, or $\mathrm{CO}_{2}$ plus methanol (Figure 2B) suggested facultative methylotrophy with a preference for methanol and/or a slower growth rate on multi-carbon substrates. Apart from the already mentioned methylotrophic families a Methylocystaceae-affiliated phylotype $\left(\mathrm{OTU}_{\mathrm{mxaF}} 137\right)$ was labeled in one multi-carbon substrate treatment (i.e., the treatments with $\left[{ }^{13} \mathrm{C}_{6}\right]$-glucose, Figure 2A). This phylotype might be only little competitve under methylotrophic conditions. Only a few mxaF phylotypes of Methylobacterium and Hyphomicrobium were solely labeled in multi-carbon substrate treatments. This observation suggests a preference for multi-carbon substrates over methanol by these phylotypes or a weak competiveness for methanol (Figure 2B). Under experimentally elevated $\mathrm{pH}$ another Methylobacterium-phylotype $\left(\mathrm{OTU}_{\mathrm{mxaF}} 55\right)$ was abundantly labeled. Its facultatively methylotrophic lifestyle can be concluded from the fact that it was labeled in both sugar and vanillic acid treatments (Figure 2B and Supplementary Table S9). Obviously, OTU $\mathrm{mxaF}_{55}$ had a preference for more neutral $\mathrm{pH}$ conditions, because it was only weakly labeled in the $\mathrm{pH} 4$ treatment (Figure 2B and Supplementary Tables S8, S9).

The fungus Cryptococcus (OTU ITS 46; Basidiomycota) was abundant in the $\mathrm{H}$ fraction of labeled fungal phylotypes in the $\left[{ }^{13} \mathrm{C}_{1}\right]$-methanol treatment of the substrate SIP experiment (Figures 3, 5). Although a general increase in the relative abundance of Cryptococcus-related phylotypes was observed in the vanillic acid treatment (Supplementary Table S12), another

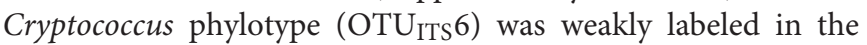
vanillic acid treatment (Figure 5). An assimilation of the methyl group of aromatic compounds is conceivable, as well as the possibility of utilizing carbon derived from the breakdown products of vanillic acid.

Three ascomycetous phylotypes (OTU $\mathrm{ITS}_{2}$, Saccharomycetes; $\mathrm{OTU}_{\mathrm{ITS}}$ 32, Oidiodendron; and OTU ITS 5, Mortierella) were labeled in the methanol and vanillic acid treatments and 




Mortierella-related phylotypes were detectable with low LPs in both methanol treatments at the in situ $\mathrm{pH}$ and the vanillic acid treatment (Figures 3, 5). The broadest substrate range was revealed by a Trichosporon-phylotype (OTU ITS 1$)$ labeled in acetate, sugar and vanillic acid treatments. Moreover, methanol utilization cannot be excluded for this phylotype because it was also labeled in the $\mathrm{pH} 7$ treatment of the $\mathrm{pH}$ shift SIP experiment, which suggests an assimilation of methanol or at least the utilization of methanol-derived carbon (Figures 3, 5).

\section{DISCUSSION}

Stable isotope probing combined with high-throughput sequencing have expanded our knowledge on the phylogenetic 


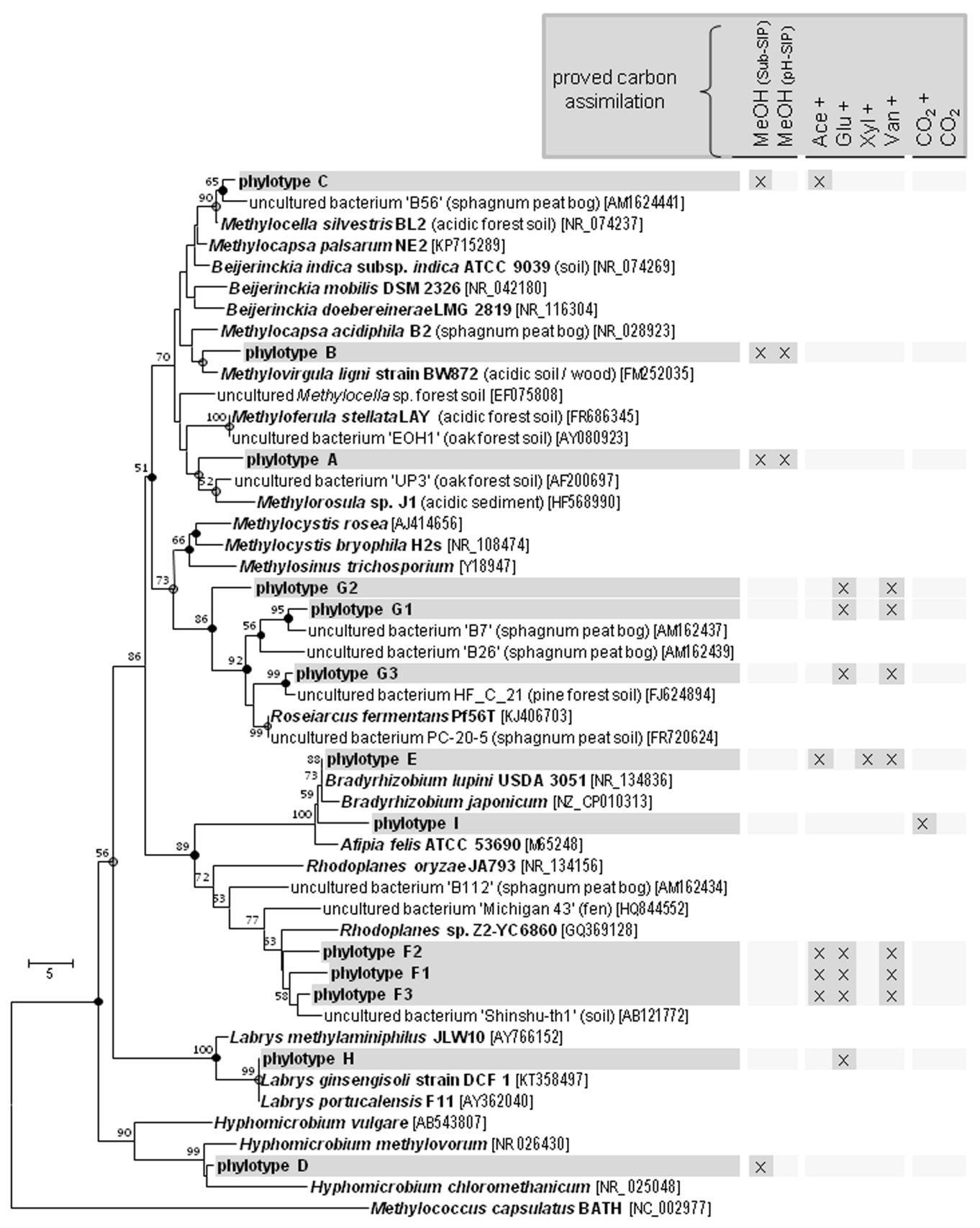

FIGURE 6 | Species-Level resolution of the Beijerinckiaceae-affiliated phylotype OTU 165438 . Species-level phylotypes of the Beijerinckiaceae-affiliated OTU $16{ }^{4} 438$ (, phylotype A to I based on species level similarity cut-off) and their putative substrate utilization. Outgroup, 16S rRNA sequence of Methylococcus capsulatus BATH. Bootstrap were based on 1000 replicated calculations. The trees was calculated with the neighborjoining method. Dots at the nodes, congruent nodes with trees caculated with the maximum likelihood and maximum parsimony method ( $\bullet$, true for three methods; $\bullet$, true for two methods). If known the isolation origin of each sequence is given in brackets. Accession numbers are given in squared brackets. The bar indicates 5 changes per nucleotide. 'Sub-SIP,' substrate SIP experiment; 'pH-SIP,' pH shift SIP experiment; cross, additional $\left[{ }^{12} \mathrm{C}\right]$-methanol supplementation in substrate treatments of the substrate SIP experiment.

diversity and global distribution of methylotrophs in terrestrial ecosystems (e.g., Kolb and Stacheter, 2013; Stacheter et al., 2013; Chistoserdova, 2015). However, their significant role in ecosystem-level methanol cycling has been largely neglected, although terrestrial ecosystems are strong sources and sinks. Thus, methylotrophs have a direct impact on global methanol fluxes and consequently on the global atmospheric chemistry (Galbally and Kirstine, 2002; Kolb, 2009; Stacheter et al., 2013). Furthermore, the role of methylotrophic yeasts and fungi, has hardly been investigated in soils as well as the impact of methanol-derived carbon on the soil microbial food web (Lueders et al., 2004; Kolb, 2009). 


\section{The Dominant Methanol-Utilizing Bacteria Possess a Restricted Substrate Range}

The main bacterial methanol-utilizers were affiliated with Beijerinckiaceae. This finding is consistent with studies on other acidic soils and species descriptions of acidophilic methylotrophic Beijerinckiaceae (Radajewski et al., 2000, 2002; Dedysh et al., 2001, 2006; Morris et al., 2002; Marín and Arahal, 2013 and references therein). The genera Chelatococcus and Camelimonas were excluded from all considerations on Beijerinckiaceae, since they are not capable of $\mathrm{C}_{1}$ compound utilization (Dedysh et al., 2016). Beijerinckiaceae comprises strains with remarkably different metabolic capacities including chemoheterotrophy (Beijerinckia), facultative methylotrophy (Beijerinckia, Methylorosula, Methylovirgula), 'restricted' facultative methanotrophy (Methylocella, Methylocapsa), and obligate methanotrophy (Methylocapsa, Methyloferula) (Marín and Arahal, 2013 and references therein; Tamas et al., 2014; Dedysh et al., 2016).

The metabolic behavior of facultative methylotrophs under in situ conditions has not been resolved, since multi-carbon utilization studies are often conducted as a comparison between methylotrophic (only $\mathrm{C}_{1}$ compounds being supplemented) and multi-carbotrophic (only multi-carbon compounds being supplemented) conditions. Such studies on pure cultures of Methylobacterium extorquens AM1 revealed a high methanol oxidation capacity in the presence of alternative multi-carbon substrates (i.e., multi-carbotrophic followed by methylotrophic conditions) or mixed substrate conditions suggesting that methanol is primarily used for energy conservation (Bosch et al., 2008; Skovran et al., 2010; Peyraud et al., 2011, 2012). Regrettably, such carbon flux studies are not available for members of the Beijerinckiaceae but we assume a similar regulation phenomenon in our experiment. We detected a Beijerinckiaceae-affiliated phylotype (OTU ${ }_{16 S} 438$ ), that comprises different trophic types on species-level resolution. However, due to the limited phylogenetic resolution of the analyzed 16S rRNA gene fragment (444 bp) and the close relation of Rhizobiales members, an unequivocal determination of the genus or species would still be rather vague. The species-level phylotypes $A, B, C$, and D were closely affiliated with known methylotrophs. The phylotypes $A, B$, and $\mathrm{D}$ were apparently limited in their substrate range to methanol only. The phylotype $\mathrm{C}$ revealed a restricted substrate range including methanol and acetate and was closely related with Methylocella, which was the first genus reported as facultatively methanotrophic (Dedysh et al., 2005a). Among the facultatively methylotrophic Beijerinckiaceae the documented multi-carbon substrate range is also usually limited to only a few carboxylic acids (Dedysh et al., 2005a; Vorobev et al., 2009; Marín and Arahal, 2013). There exist only two exceptions - (i) Beijerinckia mobilis, that is to date the only known methanolutilizer of the metabolically versatile genus Beijerinckia, and (ii) Methylorosula polaris, which exhibits a broad substrate range including sugars and polysaccharides (Dedysh et al., 2005b; Berestovskaya et al., 2012; Marín and Arahal, 2013). However, in our substrate SIP experiment none of these facultative methylotrophs assimilated carbon from multi-carbon substrates.

Apart from a direct substrate utilization several methylotrophic Beijerinckiaceae assimilate carbon at the level of $\mathrm{CO}_{2}$ such as Methyloferula, Methylorosula, and Methylovirgula (Marín and Arahal, 2013 and references therein; Vorobev et al., 2011). Thus, the oxidation of endogenous or supplemented substrates to $\mathrm{CO}_{2}$ by chemoheterotrophic microorganisms might have supported methylotrophic Beijerinckiaceae and could have led to a dilution of a conceivable ${ }^{13} \mathrm{C}$-signal, although we tried to minimize such an effect by several experimental measures.

A potentional to utilize methane was somewhat likely for some of the labeled Beijerinckiaceae-associated phylotypes since $m m o X$ genes (encoding for Beijerinckiaceae-associated sMMO) were detectable by qPCR (Dedysh et al., 2005a; Vorobev et al., 2011; Marín and Arahal, 2013). However, a final proof of their identities by sequencing of the amplicon is missing. Additionally, a growth stimulating effect of methane was also observed when comparing both methanol treatments of both SIP experiments (i.e., the substrate SIP and the $\mathrm{pH}$ shift SIP experiment), which revealed a higher LP when methane was available. Taken together, our findings suggest that (i) Beijerinckiaceae-affiliated taxa were important methanol-utilizers in the forest soil, (ii) that their substrate range might be strongly limited to methanol under in situ conditions, and (iii) that the capability of methanol utilization defines their ecological niche in a complex forest soil microbiome.

All apparently non-methylotrophic species-level members of the $\mathrm{OTU}_{16 \mathrm{~S}} 438$ (phylotypes $\mathrm{E}$ to I) affiliated with different members of Rhizobiales. For these phylotypes an assimilation of carbon derived from methanol could not be confirmed.

The phylotypes E and I were affiliated to Bradyrhizobiaceae that are trophically versatile. Methylotrophy cannot be fully excluded since Bradyrhizobium species posses xoxF genes and MDH activity but exhibit only weak growth (Kaneko et al., 2002; Sudtachat et al., 2009; Fitriyanto et al., 2011; de Souza et al., 2013). Thus, the low concentrations of methanol (i.e., $1 \mathrm{mM}$ per pulse) led likely to a low ${ }^{13} \mathrm{C}$ incorporation and might have prevented the verification of methanol utilization. The substrate range of the phylotype $\mathrm{E}$ included acetate, xylose, and vanillic acid. Utilization of methylated aromatic compounds causes an upregulated expression of $\mathrm{C}_{1}$ metabolism genes such as $x o x F$ (Ito et al., 2006). The observed ability of Bradyrhizobium species to fix $\mathrm{CO}_{2}$ is in accordance with the detection of phylotype I in the $\mathrm{CO}_{2}$ treatments (Masuda et al., 2010). Thus, $\mathrm{CO}_{2}$ fixation might have caused a dilution of the ${ }^{13} \mathrm{C}$ signal and thus prevented the proof of methanol utilization.

Phylotype $\mathrm{H}$ was affiliated to Labriaceae (Labrys). Isolates of this family possess xoxF-like genes (Beck et al., 2015). The only methylotrophic species reported to date is Labrys methylaminiphilus that utilizes methylamine and several monosaccharides, but not methanol (Miller et al., 2005). However, also L. monachus can utilize methanol to a certain extent (Miller et al., 2005). Thus, the genus Labrys might comprise hitherto unknown methanol utilizers.

The phylotypes $F$ and $G$ were closely affiliated to environmental sequences. Classification revealed an affiliation 
with Rhodoplanes (Hyphomicrobiaceae). Nonetheless, several reads of phylotype $\mathrm{F}$ were closely related with Methylocystaceae (Methylosinus) and Xanthobacteraceae (Variibacter, Pseudolabrys) rendering an unambiguous affiliation hardly possible. Interestingly, studies in peat bogs addressing methanotrophs identified also sequences somehow affiliated to Rhodoplanes by using methanotrophic specific probes (i.e., Methylosinus specific) but were also not able to verify methylotrophy of these taxa (McDonald et al., 1996, 1999). Thus, this cluster of Rhodoplanes-affiliated sequences remains enigmatic regarding methylotrophy. Another still enigmatic taxon is phylotype $G$ that was affiliated with several environmental sequences that were in turn affiliated with Methylocystaceae and Beijerinckiaceae. Within this cluster, only one species (Roseiarcus fermentans) has been taxonomically described. However, this species cannot utilize $C_{1}$ compounds (Kulichevskaya et al., 2014).

\section{Discrepancy of Identified Methanol-Utilizers Based on 16S rRNA Gene and $m x a F$}

Most mxaF phylotypes were affiliated with Methylobacteriaceae and Hyphomicrobiaceae instead of Beijerinckiaceae, and no significant similarity to $m x a F$ from a previous study on a forest soil or mxaF genes of Methylovirgula ligni was evident (Radajewski et al., 2002; Vorobev et al., 2009). Beijerinckiaceae can harbor mxaF sequences, which are similar to that of Methylobacterium or Hyphomicrobium due to horizontal gene transfer (HGT) events that occurred during the evolution of this family (Lau et al., 2013; Tamas et al., 2014).

Interestingly, one mxaF phylotype affiliated with Methylocystaceae (OTU $\mathrm{mxaF}_{137)}$ was labeled under mixed substrate conditions with glucose although Methylocystaceae were not abundant in the bacterial community based on both gene markers (16S rRNA and mxaF, Supplementary Figures S2, S8). Methylocystaceae comprise restricted facultative methanotrophs, i.e., strains of the Methylocystis slowly grow on acetate or ethanol (Belova et al., 2011). However, the utilization of glucose has never been reported. Thus, it is possible that $\mathrm{OTU}_{\mathrm{mxaF}} 137$ is a hitherto unknown glucose-utilizing member of Methylocystaceae or the specific mxaF genotype has been horizontally transferred to the methanotrophic sister genera.

Another aspect is the lack of detection of $x o x F$ genes. Both genes possess different functions and phylogenetic distributions. At the time conducting our experiments an unequivocal grouping between $m x a F$ genes and five distinct clades of $x o x F$ genes ( $x o x F 1$ to $x o x F 5$ ) was known (Chistoserdova, 2011; Keltjens et al., 2014). Only recently, $x \circ x F$ gene sequences were analyzed in detail, which enabled the development of divergent $x o x F$ primers for the different clades (Taubert et al., 2015). Thus, targeting both mxaF and $x o x F$ genes with only one primer pair might result in biased amplification results toward $m x a F$.

\section{Putative Fungal Methanol-Utilizers}

Until now, only a limited number of methylotrophic fungi belonging to yeasts or molds (mainly Ascomycota), have been reported (Kolb, 2009; Kolb and Stacheter, 2013). In our study, fungal phylotypes that assimilated methanol-derived carbon were basidiomycetous yeasts (Tremellomycetes), in particular Cryptococcus and Trichosporon, and the zygomycetous genus Mortierella. These genera are globally abundant in soil and are saprotrophs that utilize degradation products of plants (Botha, 2011; Voř́ŕšková and Baldrian, 2013). Cryptococcus species might be involved in methane cycling (Takishita et al., 2006) and can be associated with bacterial methylotrophs (Methylorosula sp.) (Delavat et al., 2013). For Trichosporon methylotrophy has been documented (Kaszycki et al., 2006). The zygomycetous Mortierella are widespread and are generalistic saprotrophic fungi with the ability to degrade complex plant material (Dix and Webster, 1995; Kjøller and Struwe, 2002; Hanson et al., 2008; Buée et al., 2009). Since Cryptococcus and Mortierella are saprotrophic and have a broad range of substrates, a labeling by cross feeding on labeled bacteria might have been an alternative route of carbon assimilation. Nevertheless, an assimilation of methanol cannot be excluded rendering these fungi new candidate methylotrophs that need further experimental attention.

\section{Influence of an Elevated pH on the Indigenous Methanol-Utilizing Microbiome}

Soil is not homogeneous and microscale habitats exist. For example, within few millimetres of soil, $\mathrm{pH}$ values can differ up to one $\mathrm{pH}$ unit (Or et al., 2007). Thus, we wanted to address if and how the indigenous methanol-utilizers might have been affected to elevated $\mathrm{pH}$ values. The total bacterial community was significantly influenced by the increased $\mathrm{pH}$ as expected (Supplementary Table S13), and the active methanol-utilizing taxa shifted compared to those under in situ $\mathrm{pH}$.

We identified phylotypes of the phyla Bacteroidetes, Actinobacteria, and Betaproteobacteria as methanol-utilizers at a neutral $\mathrm{pH}$. Among the Bacteroidetes, a small number of methylotrophs belonging to Flavobacteriia and Sphingobacteriia have been reported but none among Flavobacteriaceae (Boden et al., 2008; Madhaiyan et al., 2010; Kolb and Stacheter, 2013). Among the Actinobacteria, strains of Leifsonia are methanol utilizers (Hung et al., 2011). The detected Betaproteobacteriaaffiliated phylotype was weakly labeled at neutral $\mathrm{pH}$, but was affiliated to the well-known methylotrophic Methylophilaceae, of which isolates are neutro- to alcaliphilic (Doronina et al., 2013). Very likely, this phylotype had a lower competitiveness compared with the main bacterial methanol utilizers - i.e., Beijerinckiaceae. Although Methylophilaceae have been reported to be trophically versatile (Doronina et al., 2013), we did not detect this phylotype in any multi-carbon substrate treatment, which supports the hypothesis that this phylotype thrived in situ under unfavorable conditions.

Although the $\mathrm{pH}$ shift did not significantly affect the total fungal community (Supplementary Table S14), a reducing effect of the elevated $\mathrm{pH}$ on the alpha diversity of active methanol-derived carbon-utilizing fungi was likely based on the observation of a lower number of labeled phylotypes at neutral 
pH. Cryptococcus and Mortierella comprise several acid-tolerant species, which likely can also grow under neutral $\mathrm{pH}$ conditions (Gross and Robbins, 2000). However, their $\mathrm{pH}$ optima seem to be restricted to values $<7$, which may explain why Trichosporon outcompeted Cryptococcus and Mortierella species at $\mathrm{pH} 7$ (Gross and Robbins, 2000). The only known methylotrophic Trichosporon strain has a growth optimum of $\mathrm{pH} 8$ (Kaszycki et al., 2006). Methylotrophy was not tested at an acidic $\mathrm{pH}$. Since the Trichosporon phylotype also incorporated carbon from $\left[{ }^{13} \mathrm{C}_{\mathrm{u}}\right]$-glucose and $\left[{ }^{13} \mathrm{C}_{\mathrm{u}}\right]$-xylose at $\mathrm{pH} 4$, a broader $\mathrm{pH}$ optimum of this taxon of potentially methylotrophic soil yeasts is likely.

\section{A Methanol-Driven Microbial Food Web in the Investigated Acidic Forest Soil}

The detection of several other bacterial and fungal organisms assimilating methanol or methanol-derived carbon suggested a tight trophic link between Beijerinckiaceae and other microorganims in the soil. On the one hand Beijerinckiacea might have provided carbon sources for several bacterial taxa (i.e., Acidobacteria, Planctomycetes, non-methanotrophic Verrucomicrobia and Actinobacteria), resulting in a weak label in methanol treatments. Planctomycetes and Verrucomicrobia can degrade extracellular polysaccharides (EPSs) produced by Beijerinckiaceae (Wang et al., 2015). Peat-derived Acidobacteria were enriched with methanol, glucose, or xylan; but isolation on solely methanol was unsuccessful (Pankratov et al., 2008) suggesting an indirect stimulation. Edaphobacter aggregans that grows only in co-culture with Methylocella silvestris suggesting methylotrophic Beijerinckiaceae as effective suppliers of carbon through EPS formation (Koch et al., 2008). Actinobacteria might also utilize other compounds of Beijerinckiaceae. Kineosporia spp. (OTU ${ }_{165} 703$, Actinomycetales) can grow on DNA (Kudo et al., 1998) and therefore both DNA and EPS from Beijerinckiaceae might have served as carbon sources. Furthermore, autotrophic growth has been reported for some Acidimicrobiales (Johnson et al., 2009) and methanotrophic Verrucomicrobia (Khadem et al., 2011; Sharp et al., 2014). Since we detected Verrucomicrobia by SIP in treatments that were supplemented with ${ }^{13} \mathrm{CO}_{2}$, cross labeling through ${ }^{13} \mathrm{CO}_{2}$ was somewhat likely, although we regularly exchanged the headspace atmosphere to minimize this experimental artifact.

On the other hand, soil Beijerinckiaceae might feed on methanol released by fungi during lignin decomposition (Messner et al., 2003). An example, for which such a trophic link has been suggested is Methylovirgula ligni isolated from a decaying wood that was substantially colonized by a whiterot fungus (Folman et al., 2008; Vorobev et al., 2009). The same might be true for members of the Actinobacteria (i.e., Actinomycetes) and Planctomycetes (i.e., Phycisphaerae) of which both members of both phyla might be involved in biopolymer degradation (McCarthy, 1978; Suneetha and Khan, 2010; Bienhold et al., 2013). Thus, it is conceivable that the fungal and bacterial activity increased the local concentration of methanol when degrading plant residues and thus support methylotrophic Beijerinckiaceae.

\section{CONCLUSION}

Our study revealed acidotolerant Beijerinckiaceae as the main bacterial methanol sink in a decidous forest soil and highlights their importance for the conversion of methanol in forest soils. These methanol-utilizing Bacteria revealed a clear preference for $\mathrm{C}_{1}$ compounds that likely enabled them to establish in a complex soil microbiome. The utilization of methanol as sole energy source of various taxa of this family cannot be excluded. We also detected soil yeasts, such as Cryptococcus and Trichosporon, and saprotrophic Mortierella, which suggests that these fungi need to be carefully checked if they are indeed not able to grow on methanol. A putative carbon crossfeeding due to secondarily ${ }^{13} \mathrm{C}$-assimilation especially for fungal species (saprotrophic fungi) cannot be excluded. Nonetheless, the headspace of experimental flasks were reguarly flushed with fresh air and ${ }^{12} \mathrm{CO}_{2}$ was added to dilute formed to prevent ${ }^{13} \mathrm{CO}_{2}$ labeling through this compound. The observed and discussed aspects of the interaction of Beijerinckiaceae, yeasts, fungi, and non-methylotrophic heterotrophic Bacteria suggests that these microorganisms are tightly trophically linked through methanol release from plant organs and residues in the surface soil horizons of deciduous temperate forests. Eventually, we provided evidence that soil $\mathrm{pH}$ and the substrate spectrum are crucial factors that define the ecological niches of soil methanol utilizers.

\section{AUTHOR CONTRIBUTIONS}

MM conducted the experiments and wrote the first draft of the manuscript. HH, DKW, GL, and TW analyzed ITS data and contributed to interretation of fungi-associated results. EK supported bioinformatic amplicon analysis and was involved in the interpretation of the data. SK conceptualized the study and wrote the manuscript.

\section{ACKNOWLEDGMENTS}

This study was funded by grants of the Deutsche Forschungsgemeinschaft (DFG Ko 2912/5-1) and funds of the Institute of Landscape Biogeochemistry at the Leibniz Centre for Agricultural Research e.V. (ZALF) (Müncheberg, Germany). We thank Beatrix Schnabel for technical assistance and members of the Göttingen Genomics Lab (University of Göttingen; Germany) for technical assistance with pyrosequencing. The authors are very grateful for Harold L. Drake, who hosted and supported the project at the Department of Ecological Microbiology of the University of Bayreuth (Germany).

\section{SUPPLEMENTARY MATERIAL}

The Supplementary Material for this article can be found online at: http://journal.frontiersin.org/article/10.3389/fmicb. 2017.01361/full\#supplementary-material 


\section{REFERENCES}

Beck, D. A., McTaggart, T. L., Setboonsarng, U., Vorobev, A., Goodwin, L., Shapiro, N., et al. (2015). Multiphyletic origins of methylotrophy in Alphaproteobacteria, exemplified by comparative genomics of Lake Washington isolates. Environ. Microbiol. 3, 547-554. doi: 10.1111/14622920.12736

Belova, S. E., Baani, M., Suzina, N. E., Bodelier, P. L. E., Liesack, W., and Dedysh, S. N. (2011). Acetate utilization as a survival strategy of peat-inhabiting Methylocystis spp. Environ. Microbiol. Rep. 3, 36-46. doi: 10.1111/j.1758-2229. 2010.00180.x

Berestovskaya, J. J., Kotsyurbenko, O. R., Tourova, T. P., Kolganova, T. V., Doronina, N. V., Golyshin, P. N., et al. (2012). Methylorosula polaris gen. nov., sp. nov., an aerobic, facultatively methylotrophic psychrotolerant bacterium from tundra wetland soil. Int. J. Syst. Evol. Microbiol. 62, 638-646. doi: 10.1099/ ijs.0.007005-0

Berry, D., Ben Mahfoudh, K., Wagner, M., and Loy, A. (2011). Barcoded primers used in multiplex amplicon pyrosequencing bias amplification. Appl. Environ. Microbiol. 77, 7846-7849. doi: 10.1128/AEM.05220-11

Bienhold, C., Pop Ristova, P., Wenzhöfer, F., Dittmar, T., and Boetius, A. (2013). How deep-sea wood falls sustain chemosynthetic life. PLoS ONE 8:e53590. doi: 10.1371/journal.pone.0053590

Boden, R., Thomas, E., Savani, P., Kelly, D. P., and Wood, A. P. (2008). Novel methylotrophic bacteria isolated from the River Thames (London, UK). Environ. Microbiol. 10, 3225-3236. doi: 10.1111/j.1462-2920.2008.01711.x

Bosch, G., Skovran, E., Xia, Q., Wang, T., Taub, F., Miller, J. A., et al. (2008). Comprehensive proteomics of Methylobacterium extorquens AM1 metabolism under single carbon and non methylotrophic conditions. Proteomics 8, 3494-3505. doi: 10.1002/pmic.200800152

Botha, A. (2011). The importance and ecology of yeasts in soil. Soil Biol. Biochem. 43, 1-8. doi: 10.1016/j.soilbio.2010.10.001

Bragg, L., Stone, G., Imelfort, M., Hugenholtz, P., and Tyson, G. W. (2012). Fast, accurate error-correction of amplicon pyrosequences using Acacia. Nat. Methods 9, 425-426. doi: 10.1038/nmeth.1990

Buée, M., Reich, M., Murat, C., Morin, E., Nilsson, R. H., Uroz, S., et al. (2009). 454 pyrosequencing analyzes of forest soils reveal an unexpectedly high fungal diversity. New Phytol. 184, 449-456. doi: 10.1111/j.1469-8137.2009.03003.x

Chistoserdova, L. (2011). Modularity of methylotrophy, revisited. Environ. Microbiol. 13, 2603-2622. doi: 10.1111/j.1462-2920.2011.02464.x

Chistoserdova, L. (2015). Methylotrophs in natural habitats: current insights through metagenomics. Appl. Microbiol. Biotechnol. 99, 5763-5779. doi: 10.1007/s00253-015-6713-z

Chistoserdova, L., Kalyuzhnaya, M. G., and Lidstrom, M. E. (2009). The expanding world of methylotrophic metabolism. Annu. Rev. Microbiol. 63, 477-499. doi: 10.1146/annurev.micro.091208.073600

Chistoserdova, L., and Lidstrom, M. E. (2013). "Aerobic methylotrophic prokaryotes," in The Prokaryotes - Prokaryotic Physiology and Biochemistry, eds E. Rosenberg, E. F. DeLong, S. Lory, E. Stackebrandt, and F. Thompson (New York, NY: Springer), 267-285.

Dallinger, A., and Horn, M. A. (2014). Agricultural soil and drilosphere as reservoirs of new and unusual assimilators of 2,4-dichlorophenol carbon. Environ. Microbiol. 16, 84-100. doi: 10.1111/1462-2920.12209

de Souza, J. A. M., Carrareto Alves, L. M., de Mello Varani, A., and de Macedo Lemos, E. G. (2013). “The family Bradyrhizobiaceae," in The Prokaryotes Alphaproteobacteria and Betaproteobacteria, eds E. Rosenberg, E. F. DeLong, S. Lory, E. Stackebrandt, and F. Thompson (New York, NY: Springer), 135-154.

Dedysh, S. N., Derakshani, M., and Liesack, W. (2001). Detection and enumeration of methanotrophs in acidic Sphagnum peat by $16 \mathrm{~S}$ rRNA fluorescence in situ hybridization, including the use of newly developed oligonucleotide probes for Methylocella palustris. Appl. Environ. Microbiol. 67, 4850-4857. doi: 10.1128/ AEM.67.10.4850-4857.200

Dedysh, S. N., Haupt, E. S., and Dunfield, P. F. (2016). Emended description of the family Beijerinckiaceae and transfer of the genera Chelatococcus and Camelimonas to the family Chelatococcaceae fam. nov. Int. J. Syst. Evol. Microbiol. 66, 3177-3182. doi: 10.1099/ijsem.0.001167

Dedysh, S. N., Knief, C., and Dunfield, P. F. (2005a). Methylocella species are facultatively methanotrophic. J. Bacteriol. 187, 4665-4670. doi: 10.1128/JB.187. 13.4665-4670.2005
Dedysh, S. N., Pankratov, T. A., Belova, S. E., Kulichevskaya, I. S., and Liesack, W. (2006). Phylogenetic analysis and in situ identification of bacteria community composition in an acidic Sphagnum peat bog. Appl. Environ. Microbiol. 72, 2110-2117. doi: 10.1128/AEM.72.3.2110-2117.2006

Dedysh, S. N., Smirnova, K. V., Khmelenina, V. N., Suzina, N. E., Liesack, W., Yuri, A., et al. (2005b). Methylotrophic autotrophy in Beijerinckia mobilis. J. Bacteriol. 187, 3884-3888.

Degelmann, D. M., Borken, W., Drake, H. L., and Kolb, S. (2010). Different atmospheric methane-oxidizing communities in European beech and Norway spruce soils. Appl. Environ. Microbiol. 76, 3228-3235. doi: 10.1128/AEM. 02730-09

Degelmann, D. M., Borken, W., and Kolb, S. (2009). Methane oxidation kinetics differ in European beech and Norway spruce soils. Eur. J. Soil Sci. 60, 499-506. doi: 10.1111/j.1365-2389.2009.01138.x

Delavat, F., Lett, M. C., and Lièvremont, D. (2013). Yeast and bacterial diversity along a transect in an acidic, As-Fe rich environment revealed by cultural approaches. Sci. Total Environ. 46, 823-828. doi: 10.1016/j.scitotenv.2013. 06.023

Dix, N. J., and Webster, J. (1995). Fungal Ecology. London: Chapman and Hall.

Doronina, N., Kaparullina, E., and Trotsenko, Y. (2013). "The family Methylophilaceae," in The Prokaryotes - Alphaproteobacteria and Betaproteobacteria, eds E. Rosenberg, E. F. DeLong, S. Lory, E. Stackebrandt, and F. Thompson (New York, NY: Springer), 869-880.

Edgar, R. C., Haas, B. J., Clemente, J. C., Quince, C., and Knight, R. (2011). UCHIME improves sensitivity and speed of chimera detection. Bioinformatics 27, 2194-2200. doi: 10.1093/bioinformatics/btr381

Fall, R., and Benson, A. A. (1996). Leaf methanol - the simplest natural product from plants. Trends Plant Sci. 1, 296-301. doi: 10.1016/S1360-1385(96) 88175-0

Fitriyanto, N. A., Fushimi, M., Matsunaga, M., Pertiwiningrum, A., Iwama, T., and Kawai, K. (2011). Molecular structure and gene analysis of $\mathrm{Ce}^{3+}$ induced methanol dehydrogenase of Bradyrhizobium sp. MAFF211645. J. Biosci. Bioeng. 6, 613-617. doi: 10.1016/j.jbiosc.2011.01.015

Foerstner, K. U., von Mering, C., Hooper, S. D., and Bork, P. (2005). Environments shape the nucleotide composition of genomes. EMBO Rep. 6, 1208-1213. doi: 10.1038/sj.embor.7400538

Folman, L. B., Klein Gunnewiek, P. J., Boddy, L., and de Boer, W. (2008). Impact of white-rot fungi on numbers and community composition of bacteria colonizing beech wood from forest soil. FEMS Microbiol. Ecol. 63, 181-191. doi: 10.1111/j. 1574-6941.2007.00425.x

Fu, L., Niu, B., Zhu, Z., Wu, S., and Li, W. (2012). CD-HIT: accelerated for clustering the next-generation sequencing data. Bioinformatics 28, 3150-3152. doi: 10.1093/bioinformatics/bts565

Galbally, I. E., and Kirstine, W. (2002). The production of methanol by flowering plants and the global cycle of methanol. J. Atmos. Chem. 43, 195-229. doi: 10.1023/A:1020684815474

Gardes, M., and Bruns, T. D. (1993). ITS primers with enhanced specificity for basidiomycetes - application to the identification of mycorrhizae and rusts. Mol. Ecol. 2, 113-118. doi: 10.1111/j.1365-294X.1993.tb00005.x

Griffiths, R. I., Whiteley, A. S., O'Donnell, A. G., and Bailey, M. J. (2000). Rapid method for coextraction of DNA and RNA from natural environments for analysis of ribosomal DNA- and rRNA-based microbial community composition. Appl. Environ. Microbiol. 66, 5488-5491. doi: 10.1128/AEM.66. 12.5488-5491.2000

Gross, S., and Robbins, E. I. (2000). Acidophilic and acid-tolerant fungi and yeasts. Hydrobiologia 433, 91-109. doi: 10.1023/A:1004014603333

Gvozdev, A. R., Tukhvatullin, I. A., and Gvozdev, R. I. (2012). Quinone-dependent alcohol dehydrogenases and FAD-dependent alcohol oxidases. Biochemistry 77, 843-856. doi: 10.1134/S0006297912080056

Hanson, C. A., Allison, S. D., Bradford, M. A., Wallenstein, M. D., and Treseder, K. K. (2008). Fungal taxa target different carbon sources in forest soil. Ecosystems 11, 1157-1167. doi: 10.1007/s10021-008-9186-4

Hedderich, R., and Withman, W. B. (2013). "Physiology and biochemistry of the methane-producing Archaea," in The Prokaryotes - Prokaryotic Physiology and Biochemistry, eds E. Rosenberg, E. F. DeLong, S. Lory, E. Stackebrandt, and F. Thompson (New York, NY: Springer), 635-662.

Herlemann, D. P., Labrenz, M., Jürgens, K., Bertilsson, S., Waniek, J. J., and Andersson, A. F. (2011). Transitions in bacterial communities along the 
2000km salinity gradient of the Baltic Sea. ISME J. 5, 1571-1579. doi: 10.1038/ ismej.2011.41

Holmes, A. J., Costello, A., Lidstrom, M. E., and Murrell, J. C. (1995). Evidence that particulate methane monooxygenase and ammonia monooxygenase may be evolutionarily related. FEMS Microbiol. Lett. 132, 203-208. doi: 10.1111/j. 1574-968.1995.tb07834.x

Hung, W.-L., Wade, W. G., Boden, R., Kelly, D. P., and Wood, A. P. (2011). Facultative methylotrophs from the human oral cavity and methylotrophy in strains of Gordonia, Leifsonia, and Microbacterium. Arch. Microbiol. 193, 407-417. doi: 10.1007/s00203-011-0689-6

Ito, N., Itakura, M., Eda, S., Saeki, K., Oomori, H., Yokoyama, T., et al. (2006). Global gene expression in Bradyrhizobium japonicum cultured with vanillin, vanillate, 4-hydroxybenzoate and protocatechuate. Microbes Environ. 21, 240-250. doi: 10.1264/jsme2.21.240

Johnson, D. B., Bacelar-Nicolau, P., Okibe, N., Thomas, A., and Hallberg, K. B. (2009). Ferrimicrobium acidiphilum gen. nov., sp. nov. and Ferrithrix thermotolerans gen. nov., sp. nov.: heterotrophic, iron-oxidizing, extremely acidophilic Actinobacteria. Int. J. Syst. Evol. Microbiol. 59, 1082-1089. doi: 10.1099/ijs.0.65409-0

Kalyuzhnaya, M. G., Hristova, K. R., Lidstrom, M. E., and Chistoserdova, L. (2008). Characterization of a novel methanol dehydrogenase in representatives of Burkholderiales: implications for environmental detection of methylotrophy and evidence for convergent evolution. J. Bacteriol. 190, 3817-3823. doi: 10.1128/JB.00180-08

Kaneko, T., Nakamura, Y., Sato, S., Minamisawa, K., Uchiumi, T., Sasamoto, S., et al. (2002). Complete genomic sequence of nitrogen-fixing symbiotic bacterium Bradyrhizobium japonicum USDA110. DNA Res. 9, 189-197. doi: 10.1093/dnares/9.6.189

Kaszycki, P., Czechowska, K., Petryszak, P., Miêdzobrodzki, J., Pawlik, B., and Kołoczek, H. (2006). Methylotrophic extremophilic yeast Trichosporon sp.: a soil-derived isolate with potential applications in environmental biotechnology. Acta Biochim. Pol. 53, 463-473.

Keltjens, J. T., Pol, A., Reimann, J., and Op den Camp, H. J. (2014). PQQdependent methanol dehydrogenases: rare-earth elements make a difference. Appl. Microbiol. Biotechnol. 98, 6163-6183. doi: 10.1007/s00253-014-5766-8

Khadem, A. F., Pol, A., Wieczorek, A., Mohammadi, S. S., Francoijs, K. J., Stunnenberg, H. G., et al. (2011). Autotrophic methanotrophy in Verrucomicrobia: Methylacidiphilum fumariolicum SolV uses the CalvinBenson-Bassham cycle for carbon dioxide fixation. J. Bacteriol. 193, 4438-4446. doi: 10.1128/JB.00407-11

Kjøller, A. H., and Struwe, S. (2002). "Fungal communities, succession, enzymes, and decomposition," in Enzymes in the Environment: Activity, Ecology and Applications, eds R. G. Burns and R. P. Dick (New York, NY: Marcel Dekker, Inc), 267-284.

Klindworth, A., Pruesse, E., Schweer, T., Peplies, J., Quast, C., Horn, M., et al. (2013). Evaluation of general 16 S ribosomal RNA gene PCR primers for classical and next-generation sequencing-based diversity studies. Nucleic Acids Res. 41, e1. doi: $10.1093 / \mathrm{nar} / \mathrm{gks} 808$

Koch, I. H., Gich, F., Dunfield, P. F., and Overmann, J. (2008). Edaphobacter modestus gen. nov., sp. nov., and Edaphobacter aggregans sp. nov., Acidobacteria isolated from alpine and forest soils. Int. J. Syst. Evol. Microbiol. 58, 1114-1122. doi: $10.1099 /$ ijs.0.65303-0

Kolb, S. (2009). Aerobic methanol-oxidizing Bacteria in soil. FEMS Microbiol. Lett. 300, 1-10. doi: 10.1111/j.1574-6968.2009.01681.x

Kolb, S., Knief, C., Dunfield, P. F., and Conrad, R. (2005). Abundance and activity of uncultured methanotrophic bacteria involved in the consumption of atmospheric methane in two forest soils. Environ. Microbiol. 7, 1150-1161. doi: 10.1111/j.1462-2920.2005.00791.x

Kolb, S., and Stacheter, A. (2013). Prerequisites for amplicon pyrosequencing of microbial methanol-utilizers in the environment. Front. Microbiol. 4:268. doi: $10.3389 /$ fmicb. 2013.00268

Kõljalg, U., Nilsson, R. H., Abarenkov, K., Tedersoo, L., Taylor, A. F., Bahram, M., et al. (2013). Towards a unified paradigm for sequence-based identification of fungi. Mol. Ecol. 22, 5271-5277. doi: 10.1111/mec.12481

Kudo, T., Matsushima, K., Itoh, T., Sasaki, J., and Suzuki, K. (1998). Description of four new species of the genus Kineosporia: Kineosporia succinea sp. nov., Kineosporia rhizophila sp. nov., Kineosporia mikuniensis sp. nov. and Kineosporia rhamnosa sp. nov., isolated from plant samples, and amended description of the genus Kineosporia. Int. J. Syst. Evol. Microbiol. 48, 1245-1255. doi: 10.1099/00207713-48-4-1245

Kulichevskaya, I. S., Danilova, O. V., Tereshina, V. M., Kevbrin, V. V., and Dedysh, S. N. (2014). Descriptions of Roseiarcus fermentans gen. nov., sp. nov., a bacteriochlorophyll a-containing fermentative bacterium related phylogenetically to alphaproteobacterial methanotrophs, and of the family Roseiarcaceae fam. nov. Int. J. Syst. Evol. Microbiol. 64, 2558-2565. doi: 10.1099/ ijs.0.064576-0

Lau, E., Fisher, M. C., Steudler, P. A., and Cavanaugh, C. M. (2013). The methanol dehydrogenase gene, $m x a F$, as a functional and phylogenetic marker for proteobacterial methanotrophs in natural environments. PLoS ONE 8:e56993. doi: 10.1371/journal.pone.0056993

Loew, O. (1892). Ueber einen Bacillus, welcher ameisensäure und formaldehyd assimiliren kann. Centralbl. Bakteriol. 12, 462-465.

Lueders, T., Manefield, M., and Friedrich, M. W. (2004). Enhanced sensitivity of DNA- and rRNA-based stable isotope probing by fractionation and quantitative analysis of isopycnic centrifugation gradients. Environ. Microbiol. 6, 73-78. doi: 10.1046/j.1462-2920.2003.00536.x

Madhaiyan, M., Poonguzhali, S., Lee, J.-S., Senthilkumar, M., Lee, K. C., and Sundaram, S. (2010). Mucilaginibacter gossypii sp. nov. and Mucilaginibacter gossypiicola sp. nov., plant-growth-promoting bacteria isolated from cotton rhizosphere soils. J. Syst. Evol. Microbiol. 60, 2451-2457. doi: 10.1099/ijs.0. 018713-0

Marín, I., and Arahal, D. R. (2013). "The family Beijerinckiaceae," in The Prokaryotes - Alphaproteobacteria and Betaproteobacteria, eds E. Rosenberg, E. F. DeLong, S. Lory, E. Stackebrandt, and F. Thompson (New York, NY: Springer), 115-133.

Masuda, S., Eda, S., Sugawara, C., Mitsui, H., and Minamisawa, K. (2010). The $c b b L$ gene is required for thiosulfate-dependent autotrophic growth of Bradyrhizobium japonicum. Microbes Environ. 25, 220-223.

McCarthy, A. J. (1978). Lignocellulose-degrading Actinomycetes. FEMS Microbiol. Rev. 46, 145-163. doi: 10.1111/j.1574-6968.1987.tb02456.x

McDonald, I. R., Hall, G. H., Pickup, R. W., and Murrell, J. C. (1996). Methane oxidation potential and preliminary analysis of methanotrophs in blanket bog peat using molecular ecology techniques. FEMS Microbiol. Ecol. 21, 197-211. doi: 10.1111/j.1574-6941.1996.tb00347.x

McDonald, I. R., and Murrell, J. C. (1997). The methanol dehydrogenase structural gene $m x a F$ and its use as a functional gene probe for methanotrophs and methylotrophs. Appl. Environ. Microbiol. 63, 3218-3224.

McDonald, I. R., Upton, M., Hall, G., Pickup, R. W., Edwards, C., Saunders, J. R., et al. (1999). Molecular ecological analysis of methanogens and methanotrophs in blanket bog peat. Microb. Ecol. 38, 225-233. doi: 10.1007/s002489900172

Messner, K., Fackler, K., Lamaipis, P., Gindl, W., Srebotnik, E., and Watanabe, T. (2003). "Overview of white-rot research: where we are today," in Wood Deterioration and Preservation: Advances in Our Changing World (ACS Symposium Series 845), eds B. Goodell, D. D. Nicholas, and T. R. Schultz (Washington, DC: American Chemical Society), 73-96.

Miller, J. A., Kalyuzhnaya, M. G., Noyes, E., Lara, J. C., Lidstrom, M. E., and Chistoserdova, L. (2005). Labrys methylaminiphilus sp. nov., a novel facultatively methylotrophic bacterium from a freshwater lake sediment. Int. J. Syst. Evol. Microbiol. 55, 1247-1253. doi: 10.1099/ijs.0.63409-0

Millet, D. B., Jacob, D. J., Custer, T. G., de Gouw, J. A., Goldstein, A. H., Karl, T., et al. (2008). New constraints on terrestrial and oceanic sources of atmospheric methanol. Atmos. Chem. Phys. 8, 6887-6905. doi: 10.5194/acp-8-688 7-2008

Moosvi, S. A., McDonald, I. R., Pearce, D. A., Kelly, D. P., and Wood, A. P. (2005). Molecular detection and isolation from Antarctica of methylotrophic bacteria able to grow with methylated sulfur compounds. Syst. Appl. Microbiol. 28, 541-554. doi: 10.1016/j.syapm.2005.03.002

Morris, S. A., Radajewski, S., Willison, T. W., and Murrell, J. C. (2002). Identification of the functionally active methanotroph population in a peat soil microcosm by stable-isotope probing. Appl. Environ. Microbiol. 68, 1446-1453. doi: 10.1128/AEM.68.3.1446-1453.2002

Muyzer, G., Brinkhoff, T., Nuebel, U., Santegoeds, C., Schäfer, H., and Waver, C. (1998). "Denaturing gradient gel electrophoresis (DGGE) in microbial ecology," in Molecular Microbial Ecology Manual, eds A. D. L. Akkermans, J. D. van Elsas, and F. J. de Bruijn (Dordrecht: Kluwer Academic Publishers), $1-27$. 
Nebel, M. E., Wild, S., Holzhauser, M., Hüttenberger, L., Reitzig, R., Sperber, M., et al. (2011). Jaguc - a software package for environmental diversity analyzes. J. Bioinform. Comput. Biol. 9, 749-773. doi: 10.1142/S0219720011005781

Neufeld, J. D., Vohra, J., Dumont, M. G., Lueders, T., Manefield, M., Friedrich, M. W., et al. (2007). DNA stable-isotope probing. Nat. Protoc. 2, 860-866. doi: 10.1038/nprot.2007.109

Or, D., Smets, B. F., Wraith, J. M., Dechesne, A., and Friedman, S. P. (2007). Physical constraints affecting bacterial habitats and activity in unsaturated porous media - a review. Adv. Water Resour. 30, 1505-1527. doi: 10.1016/j. advwatres.2006.05.025

Pankratov, T. A., Serkebaeva, Y. M., Kulichevskaya, I. S., Liesack, W., and Dedysh, S. N. (2008). Substrate-induced growth and isolation of Acidobacteria from acidic Sphagnum peat. ISME J. 2, 551-560. doi: 10.1038/ismej.2008.7

Peyraud, R., Kiefer, P., Christen, P., Portais, J.-C., and Vorholt, J. A. (2012). Co-Consumption of methanol and succinate by Methylobacterium extorquens AM1. PLoS ONE 7:e48271. doi: 10.1371/journal.pone.0048271

Peyraud, R., Schneider, K., Kiefer, P., Massou, S., Vorholt, J. A., and Portais, J.-C. (2011). Genome-scale reconstruction and system level investigation of the metabolic network of Methylobacterium extorquens AM1. BMC Syst. Biol. 5:189. doi: 10.1186/1752-0509-5-189

Radajewski, S., Ineson, P., Parekh, N. R., and Murrell, J. C. (2000). Stable-isotope probing as a tool in microbial ecology. Nature 403, 646-649. doi: 10.1038/ 35001054

Radajewski, S., Webster, G., Reay, D. S., Morris, S. A., Ineson, P., Nedwell, D. B., et al. (2002). Identification of active methylotroph populations in an acidic forest soil by stable-isotope probing. Microbiology 148, 2331-2342. doi: 10.1099/ 00221287-148-8-2331

Schloss, P. D., Westcott, S. L., Ryabin, T., Hall, J. R., Hartmann, M., Hollister, E. B., et al. (2009). Introducing mothur: open-source, platform-independent, community-supported software for describing and comparing microbial communities. Appl. Environ. Microbiol. 75, 7537-7541. doi: 10.1128/AEM. 01541-09

Sharp, C. E., Smirnova, A. V., Graham, J. M., Stott, M. B., Khadka, R., Moore, T. R., et al. (2014). Distribution and diversity of Verrucomicrobia methanotrophs in geothermal and acidic environments. Environ. Microbiol. 16, 1867-1878. doi: $10.1111 / 1462-2920.12454$

Skovran, E., Crowther, G. J., Guo, X., Yang, S., and Lidstrom, M. E. (2010). A systems biology approach uncovers cellular strategies used by Methylobacterium extorquens AM1 during the switch from multi- to singlecarbon growth. PLoS ONE 5:e14091. doi: 10.1371/journal.pone.0014091

Stacheter, A., Noll, M., Lee, C. K., Selzer, M., Glowik, B., Ebertsch, L., et al. (2013). Methanol oxidation by temperate soils and environmental determinants of associated methylotrophs. ISME J. 7, 1051-1064. doi: 10.1038/ismej.2012.167

Sudtachat, N., Ito, N., Itakura, M., Masuda, S., Eda, S., Mitsui, H., et al. (2009). Aerobic vanillate degradation and C1 compound metabolism in Bradyrhizobium japonicum. Appl. Environ. Microbiol. 75, 5012-5017. doi: 10.1128/AEM.00755-09

Suneetha, V., and Khan, Z. A. (2010). “Actinomycetes: sources for soil enzymes”, in Soil Enzymology 22, eds G. Shukla and A. Varma (Berlin: Springer), 259-269.

Takishita, K., Tsuchiya, M., Reimer, J. D., and Maruyama, T. (2006). Molecular evidence demonstrating the basidiomycetous fungus Cryptococcus curvatus is the dominant microbial eukaryote in sediment at the Kuroshima knoll methane seep. Extremophiles 10, 165-169. doi: 10.1007/s00792-005-0495-7

Tamas, I., Smirnova, A. V., He, Z., and Dunfield, P. F. (2014). The (d)evolution of methanotrophy in the Beijerinckiaceae - a comparative genomics analysis. ISME J. 8, 369-382. doi: 10.1038/ismej.2013.145

Tamura, K., Stecher, G., Peterson, D., Filipski, A., and Kumar, S. (2013). MEGA6: molecular evolutionary genetics analysis version 6.0. Mol. Biol. Evol. 30, 2725-2729. doi: 10.1093/molbev/mst197

Taubert, M., Grob, C., Howat, A. M., Burns, O. J., Dixon, J. L., Chen, Y., et al. (2015). XoxF encoding an alternative methanol dehydrogenase is widespread in coastal marine environments. Environ. Microbiol. 17, 3937-3948. doi: 10.1111/ 1462-2920.12896
Voříšková, J., and Baldrian, P. (2013). Fungal community on decomposing leaf litter undergoes rapid successional changes. ISME J. 7, 477-486. doi: 10.1038/ ismej.2012.116

Vorobev, A. V., Baani, M., Doronina, N. V., Brady, A. L., Liesack, W., Dunfield, P. F., et al. (2011). Methyloferula stellata gen. nov., sp. nov., an acidophilic, obligately methanotrophic bacterium that possesses only a soluble methane monooxygenase. Int. J. Syst. Evol. Microbiol. 61, 2456-2463. doi: 10.1099/ijs.0. 028118-0

Vorobev, A. V., de Boer, W., Folman, L. B., Bodelier, P. L. E., Doronina, N. V., Suzina, N. E., et al. (2009). Methylovirgula ligni gen. nov., sp. nov., an obligately acidophilic, facultatively methylotrophic bacterium with a highly divergent mxaF gene. Int. J. Syst. Evol. Microbiol. 59, 2538-2545. doi: 10.1099/ijs.0. 010074-0

Wang, Q., Garrity, G. M., Tiedje, J. M., and Cole, J. R. (2007). Naive bayesian classifier for rapid assignment of rRNA sequences into the new bacterial taxonomy. Appl. Environ. Microbiol. 73, 5261-5267. doi: 10.1128/AEM. 00062-07

Wang, X., Sharp, C. E., Jones, G. M., Grasby, S. E., Brady, A. L., and Dunfield, P. F. (2015). Stable-isotope probing identifies uncultured Planctomycetes as primary degraders of a complex heteropolysaccharide in soil. Appl. Environ. Microbiol. 81, 4607-4615. doi: 10.1128/AEM.00055-15

Warneke, C., Karl, T., Judmaier, H., Hansel, A., Jordan, A., and Lindinger, W. (1999). Acetone, methanol, and other partially oxidized volatile organic emissions from dead plant matter by abiological processes: significance for atmospheric HOx chemistry. Glob. Biogeochem. Cycles 13, 9-17. doi: 10.1029/ 98GB02428

White, T. J., Bruns, T. D., Lee, S. B., and Taylor, J. W. (1990). "Amplification and direct sequencing of fungal ribosomal RNA genes for phylogenetics," in PCR Protocols - a Guide to Methods and Applications, eds M. A. Innis, D. H. Gelfand, J. J. Sninsky, and T. J. White (Zürich: Academic Press), 315-322.

Whittenbury, R., Philips, K. C., and Wilkinson, J. F. (1970). Enrichment, isolation, and some properties of methane-utilizing bacteria. J. Gen. Microbiol. 61, 205-218. doi: 10.1099/00221287-61-2-205

Wohlfahrt, G., Amelynck, C., Ammann, C., Arneth, A., Bamberger, I., Goldstein, A. H., et al. (2015). An ecosystem-scale perspective of the net land methanol flux: synthesis of micrometeorological flux measurements. Atmos. Chem. Phys. 15, 7413-7427. doi: 10.5194/acp-15-7413-2015

Wubet, T., Christ, S., Schöning, I., Boch, S., Gawlich, M., Schnabel, B., et al. (2012). Differences in soil fungal communities between European beech (Fagus sylvatica L.) dominated forests are related to soil and understory vegetation. PLOS ONE 7:e47500. doi: 10.1371/journal.pone. 0047500

Yarza, P., Ludwig, W., Euzéby, J., Amann, R., Schleifer, K.-H., Glöckner, F. O., et al. (2010). Update of the all-species living tree project based on $16 \mathrm{~S}$ and 23S rRNA sequence analyzes. Syst. Appl. Microbiol. 33, 291-299. doi: 10.1016/j. syapm.2010.08.001

Zaprasis, A., Liu, Y.-J., Liu, S.-J., Drake, H. L., and Horn, M. A. (2010). Abundance of novel and diverse $t f d A$-like genes, encoding putative phenoxyalkanoic acid herbicide-degrading dioxygenases, in soil. Appl. Environ. Microbiol. 76, 119-128. doi: 10.1128/AEM.01727-09

Conflict of Interest Statement: The authors declare that the research was conducted in the absence of any commercial or financial relationships that could be construed as a potential conflict of interest.

Copyright (C) 2017 Morawe, Hoeke, Wissenbach, Lentendu, Wubet, Kröber and Kolb. This is an open-access article distributed under the terms of the Creative Commons Attribution License (CC BY). The use, distribution or reproduction in other forums is permitted, provided the original author(s) or licensor are credited and that the original publication in this journal is cited, in accordance with accepted academic practice. No use, distribution or reproduction is permitted which does not comply with these terms. 